


\section{IMPACT OF COVID-19 ON CAREC AVIATION AND TOURISM}

FEBRUARY 2021

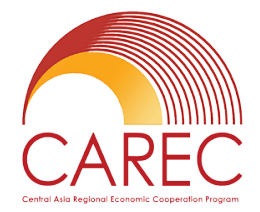


(C) 2021 Asian Development Bank

6 ADB Avenue, Mandaluyong City, 1550 Metro Manila, Philippines

Tel +632 8632 4444; Fax +63286362444

www.adb.org

Some rights reserved. Published in 2021.

ISBN 978-92-9262-698-3 (print); 978-92-9262-699-0 (electronic); 978-92-9262-700-3 (ebook)

Publication Stock No. SPR210019-2

DOI: http://dx.doi.org/10.22617/SPR210019-2

The views expressed in this publication are those of the authors and do not necessarily reflect the views and policies of the Asian Development Bank (ADB) or its Board of Governors or the governments they represent.

ADB does not guarantee the accuracy of the data included in this publication and accepts no responsibility for any consequence of their use. The mention of specific companies or products of manufacturers does not imply that they are endorsed or recommended by ADB in preference to others of a similar nature that are not mentioned.

By making any designation of or reference to a particular territory or geographic area, or by using the term "country" in this document, $A D B$ does not intend to make any judgments as to the legal or other status of any territory or area.

This work is available under the Creative Commons Attribution 3.0 IGO license (CC BY 3.0 IGO)

https://creativecommons.org/licenses/by/3.o/igo/. By using the content of this publication, you agree to be bound by the terms of this license. For attribution, translations, adaptations, and permissions, please read the provisions and terms of use at https://www.adb.org/terms-use\#openaccess.

This CC license does not apply to non-ADB copyright materials in this publication. If the material is attributed to another source, please contact the copyright owner or publisher of that source for permission to reproduce it. $\mathrm{ADB}$ cannot be held liable for any claims that arise as a result of your use of the material.

Please contact pubsmarketing@adb.org if you have questions or comments with respect to content, or if you wish to obtain copyright permission for your intended use that does not fall within these terms, or for permission to use the ADB logo.

Corrigenda to ADB publications may be found at http://www.adb.org/publications/corrigenda.

Note:

In this publication, “\$” refers to United States dollars.

Cover design by Jasper Lauzon.

On the cover: The coronavirus disease (COVID-19) pandemic as greatly affected various sectors. In Nur-Sultan, Kazakhstan, the quarantine caused many airline companies at the Nursultan Nazarbayev International Airport to shut down temporarily (photos Turar Kazangapov). 


\section{Contents}

Tables and Figures

Scope of Study

v

Preface

vi

Abbreviations

vii

1 Introduction

2 Impact Assessment Summary 3

3 Summary of Recommendations $\quad 4$

4 COVID-19 Impact on Global Air Transport and CAREC 5

A. CAREC Impact: 40 Million Fewer Airline Passengers in 2020

B. CAREC Impact: 46 Million Fewer Airport Passengers in 2020

C. CAREC Impact: \$7 Billion Reduction in Passenger Revenues 11

D. CAREC Impact: 1 Million Jobs At Risk (IATA methodology) 12

E. CAREC Impact: \$11 Billion Reduction in International Visitor Spending, \$27 Billion Reduction
in Travel and Tourism Contribution to Gross Domestic Product

F. CAREC Impact: 33 Million Fewer Visitor Arrivals in 2020

G. CAREC Impact: 5.5 Million Fewer Visitor Arrivals by Air in 2020

5 CAREC Opportunities $\quad 19$

A. CAREC Opportunity: Growing Domestic and Regional Tourism 19

B. CAREC Opportunity: Creating Green Lanes Between CAREC Countries 20

C. CAREC Opportunity: Improving Air Connectivity within CAREC 23

D. CAREC Opportunity: Expand Cargo Capabilities 26

E. CAREC Opportunity: Upgrade Airports with Contactless Technologies 28

6 CAREC Needs $\quad 30$

A. CAREC Need: Government Support for Aviation and Tourism 30

B. CAREC Need: ANSP Funding to Offset Loss of Overflight Revenues 32

\section{Appendixes}

1 Mongolia Case Study $\quad 34$

2 Survey Results $\quad 42$ 


\section{Tables and Figures}

\section{Tables}

12019 Passenger Traffic for CAREC Countries and 2020 Projections $\quad 7$

22019 Airport Traffic for CAREC Countries and 2020 Projections 8

32019 Passenger Traffic for Leading Airports in CAREC 9

4 Origin and Destination Passenger Traffic for CAREC Countries, 2018

5 Travel and Tourism Jobs in CAREC Countries, 2018

6 Travel and Tourism Contribution to GDP for CAREC Countries in 2019

7 International Travel and Tourism Contribution for CAREC Countries in 2018

8 Visitor Arrivals for CAREC Countries: 2018 and 2019

9 Visitors by Air for Select CAREC Countries: 2014 and 2018

10 Intra-CAREC One-Way Weekly Seat Capacity: Before COVID-19 23

11 Examples of Underserved intra-CAREC Routes that Can Support More Frequencies 24

12 Examples of Unserved Routes Within CAREC 25

\section{Figures}

1 Tbilisi Passenger Traffic: 2006-2019 10

2 Nur-Sultan Passenger Traffic: 2006-2019 10

3 Annual Visitors to Georgia, 2006-2019 16

A1.1 Visitors to Mongolia, 1999-2019

A1.2 Mongolia Annual Domestic and International Passenger Traffic: 1999-2019 35 


\section{Scope of Study}

This study includes the following 10 countries in the Central Asia Regional Economic Cooperation (CAREC): Afghanistan, Azerbaijan, Georgia, Kazakhstan, the Kyrgyz Republic, Mongolia, Pakistan, Tajikistan, Turkmenistan, and Uzbekistan. Xinjiang Uygur and Inner Mongolia autonomous regions of the People's Republic of China (PRC) are also part of CAREC but the PRC is excluded in all data and analysis compiled in this study. Data is not available on specifically these regions of the PRC and to include all of the PRC would distort the overall data. 


\section{Preface}

This study was initially prepared expeditiously in May 2020 to provide a quick initial assessment of the impact of the coronavirus disease (COVID-19) on the aviation and tourism sectors of the Central Asia Regional Economic Cooperation (CAREC) and provide recommendations for the recovery of air travel and tourism. An initial draft of this study was completed in early June 2020, just 2 months after the aviation and tourism sectors were grounded to a halt due to the pandemic.

The initial draft was published on the CAREC website and was discussed at the CAREC National Focal Points meeting on 16 June 2020. CAREC subsequently engaged with member countries to discuss the draft, including the 11 initial recommendations, the local impact of COVID-19 on CAREC's aviation and tourism sectors, and the recovery process. A survey was distributed and returned by eight of the member countries.

The study has been updated to assess the impact of COVID-19 as of October 2020 but should not be viewed as a final analysis of the impact, given that the pandemic will continue for some time and situation remains fluid.

The Asian Development Bank (ADB) strives to continue engaging with the CAREC aviation community to understand the impact of COVID-19 and to gauge progress in implementing the measures and policies to help CAREC countries mitigate the impact and recover. This crisis provides an opportunity to reset CAREC's aviation industry through reforms, new strategies, and restructurings.

This study is just the start of a dialogue as CAREC looks to adjust the aviation pillar of the CAREC 2030 Transport Strategy to the current environment.

A CAREC Aviation workshop is planned for 2021 to help further understand requirements and facilitate development of a new long-term strategy. In the meantime, the CAREC Aviation team is available to discuss with member countries requirements and strategies for dealing with the current crisis and facilitating a fast recovery.

The CAREC Aviation program was launched following a recommendation from the Prime Minister of Pakistan at the 15th Ministerial Conference in October 2016. CAREC's first aviation workshop was held in April 2017. CAREC subsequently commissioned an aviation scoping study, which was researched in late 2017 and published in 2018. In 2019, CAREC Aviation completed missions to the Kyrgyz Republic, Mongolia, and Uzbekistan. In 2020, in addition to this study assessing the impact of COVID-19, CAREC Aviation has completed a proposal on an air pass scheme for CAREC countries and has held virtual meetings on aviationrelated topics with several CAREC countries.

The CAREC Secretariat at ADB administered and managed the production of this study. The author of this study is Brendan Sobie, an aviation consultant who has been involved with the CAREC Aviation program since early 2017 and was also co-author of the aviation scoping study. 


\section{Abbreviations}

$\begin{array}{lll}\text { ADB } & - & \text { Asian Development Bank } \\ \text { ANSP } & - & \text { air navigation service providers } \\ \text { CAREC } & - & \text { Central Asia Regional Economic Cooperation } \\ \text { COVID-19 } & - & \text { coronavirus disease } \\ \text { GDP } & - & \text { gross domestic product } \\ \text { IATA } & - & \text { International Air Transport Association } \\ \text { PRC } & - & \text { People's Republic of China } \\ \text { UNWTO } & - & \text { United Nations World Tourism Organization } \\ \text { WTTC } & - & \text { World Travel and Tourism Council }\end{array}$





\section{Introduction}

The coronavirus disease (COVID-19) pandemic has had a devastating impact on the aviation industry globally as nearly all air travel came to a halt in late March and April 2020. The Central Asia Regional Economic Cooperation (CAREC) countries were no exception as virtually all scheduled international flights were suspended and several countries also implemented bans on domestic air travel in an attempt to contain the spread of COVID-19. All CAREC countries arranged repatriation flights to bring citizens stranded overseas home but this traffic was very limited compared to normal volumes.

Domestic markets in CAREC started reopening in May and most domestic routes have now resumed. However, domestic passenger traffic is still below precrisis levels in most CAREC countries and will likely not fully recover until after the pandemic.

As of the beginning of October 2020, most international flights remained suspended and a large portion of the CAREC passenger aircraft fleet was still grounded.

There are about 25 airlines based in CAREC offering scheduled passenger services. There are a few domestic airlines but most airlines in CAREC rely mainly or entirely on the international market for generating revenues.

In most CAREC countries, scheduled international flights resumed in July, August, and September. As of October, only two CAREC countries-Mongolia and Turkmenistan-have not resumed any scheduled international flights and were still relying on chartered flights to carry repatriating citizens.

Border restrictions remain in place throughout CAREC, impacting demand for international air travel and limiting tourism. International passenger traffic volumes in CAREC now are a tiny fraction of what they were prior to the pandemic. As of September 2020, international passenger traffic to and from and within CAREC was still down by well over $90 \%$ compared to that of the previous year.

More international services are expected to gradually resume over the next several months. However, travel restrictions are likely to remain in place for several destinations, including quarantine requirements. Most CAREC citizens will also likely be wary of traveling abroad for some time and will choose to take holidays, if any, domestically.

The recovery of international passenger traffic will be very slow. International traffic is expected to still be at a small fraction of pre-crisis levels in 2021 and not fully recover until at least 2023.

The reduction in international passenger traffic for 2020 and associated reduction in tourism will have a huge economic impact. This study assesses the impact of COVID-19 on aviation and tourism in CAREC and provides some recommendations on how to potentially mitigate this impact and achieve a recovery rate that is faster than the global average. 
2020 has been an extremely challenging year for aviation and tourism. 2021 will similarly be very challenging. However, there are opportunities to use this crisis to improve CAREC's long-term position.

This crisis provides an opportunity to reset CAREC's aviation industry through reforms, new strategies, and restructurings. This study looks briefly at some of these opportunities and makes some initial recommendations. It also provides a broad level assessment of the impact on CAREC with the objective of highlighting the gravity of the current situation and starting a dialogue.

This study is intended as a first step in a wider project to fully assess the impact of COVID-19 and identify a comprehensive list of recommended measures and policies to help CAREC countries mitigate the impact and recover. As part of the next phase in this project, the Asian Development Bank aims to engage with CAREC's aviation community, which will include conducting an aviation workshop to be held in the fourth quarter of 2021. 


\section{Impact Assessment Summary}

Estimated airline traffic reduction for CAREC in 2020:

\section{0 million passengers}

Estimated airport traffic reduction for CAREC in 2020:

\section{6 million passengers}

Estimated passenger revenue impact for CAREC in 2020:

\section{$\$ 7$ billion}

Estimated travel and tourism jobs in CAREC that are at risk in 2020 (IATA methodology):

1 million jobs

Estimated reduction in international visitor spend for CAREC in 2020:

\$11 billion

Estimated reduction in travel and tourism GDP contribution for CAREC in 2020:

$\$ 27$ billion

Estimated reduction in visitor numbers for CAREC in 2020:

\section{3 million visitors}

Estimated reduction in visitor arrivals by air for CAREC in 2020:

\section{5 million visitors}

Estimated required financial support for CAREC airlines:

\section{$\$ 2$ billion}

These figures are for the following 10 CAREC countries combined: Afghanistan, Azerbaijan, Georgia, Kazakhstan, the Kyrgyz Republic, Mongolia, Pakistan, Tajikistan, Turkmenistan, and Uzbekistan. Xinjiang Uygur and Inner Mongolia autonomous regions of the People's Republic of China (PRC) are also part of CAREC but the PRC is excluded in all data and analysis compiled as part of this study. 


\section{Summary of Recommendations}

CAREC should promote domestic tourism to help facilitate a recovery of the aviation and tourism sectors during a period of much lower international traffic.

CAREC countries should consider opening green lanes to facilitate and stimulate travel and tourism within CAREC.

CAREC countries should consider implementing a visa-free policy to further facilitate travel and tourism within CAREC.

CAREC should improve air connectivity among its countries during the pandemic and after this crisis.

CAREC should consider providing incentives to support the launch of new routes connecting major cities with tourist destinations in other CAREC countries.

CAREC should invest in boosting air cargo capabilities, leveraging its strategic location between Asia and Europe, and driving increased cargo revenues for the aviation industry during a period of passenger declines.

CAREC should pursue the liberalization of its air cargo market now to facilitate air cargo movements during the pandemic and air cargo growth over the next several years.

CAREC should promote contactless air travel and invest in technologies to support digital procedures at airports.

CAREC should adopt uniform standards and regulations for air travel in the COVID-19 environment.

CAREC should consider providing financial support to airlines through loans and loan guarantees.

CAREC should consider providing general support packages to the aviation and tourism industries through benefits such as wage subsidies, tax reductions, and fee waivers.

CAREC should consider alternative funding options to offset the impact of reduced overflight revenues. 


\section{COVID-19 Impact on Global Air Transport and CAREC}

CAREC's aviation industry is proportionately more impacted by COVID-19 than the global aviation industry due to a heavy dependence on the international market.

Prior to the COVID-19 pandemic, the domestic market accounted for $59 \%$ of global passenger traffic compared to $41 \%$ for international. However, in CAREC, the domestic market accounted for only $27 \%$ of passenger traffic compared to $73 \%$ for international.

Traffic between the 10 CAREC member countries excluding the People's Republic of China (PRC) accounted for only about $3 \%$ of total CAREC traffic. Therefore, when including the $27 \%$ portion of total traffic that is domestic, only $30 \%$ of CAREC traffic consisted of passengers heading within CAREC compared to $70 \%$ outside. This is a much lower ratio of internal traffic than other regional groupings such as the Association of Southeast Asian Nations.

Globally, passenger traffic is expected to decline by $66 \%$ in $2020 .^{1}$ A full recovery to 2019 levels is not expected until 2024.

Domestic traffic will recover faster but gradually and with significant variation depending on the market. Domestic traffic will likely decline by over $40 \%$ in 2020 at a global level.

Domestic markets in countries where virus containment efforts have been successful have generally have been recovering faster than countries where containment continues to be an issue. Domestic markets that rely heavily on international tourists have also experienced a bigger decline given the sharp drop in international traffic. Domestic markets that rely mainly on local residents and have a population that is eager to resume travelingbut will generally not be able to go abroad due to international restrictions-can recover more rapidly. These types of domestic markets, which include some CAREC countries such as Kazakhstan, could be back at 2019 levels in 2021.

At a global level, international passenger traffic will decline by over $70 \%$ in 2020 and is expected to remain well below 2019 levels in 2021. Some countries will have smaller declines than others but there are very few, if any, countries that can recover earlier than 2022. The recovery of international traffic likely hinges on a COVID-19 vaccine.

This study projects a $68 \%$ decline in total CAREC passenger traffic for 2020. This is higher than the global average due mainly to CAREC's small domestic market, which is projected to decline by $37 \%$.

International Air Transport Association (IATA). 2020. Traffic Forecast Downgrade after Dismal Summer. 29 September. https://www.iata.org/en/ pressroom/pr/2020-09-29-02/. 
Domestic air travel has started recovering, and in some CAREC countries is now close to pre-COVID levels. Kazakhstan's domestic market has particularly done well in recent months and has recovered faster than the global domestic average. However, the benefit of resumed domestic travel is somewhat limited given the small size of the domestic air transport markets in most CAREC countries.

This study projects an $80 \%$ decline in CAREC international passenger traffic for 2020. This is higher than the global average as CAREC countries have been slower in reopening borders compared to other regions including Europe and the Middle East.

CAREC countries also have a high degree of seasonality with typically significantly higher passenger traffic in the summer months. Therefore, CAREC was more impacted than other regions by the loss of the summer season in 2020 .

January and February, which in 2020 experienced normal volumes of traffic globally except for the PRC, are also off-peak months for most CAREC countries. Traffic started declining in March and by the end of March, virtually all scheduled international passenger services were suspended. Several domestic markets closed entirely, and those that remained open offered a very limited number of flights. Domestic markets began reopening in May and, by early June, almost all domestic markets-in CAREC as well as globally-were open again but with reduced schedules.

Some CAREC countries were initially hoping to salvage the peak summer season by attracting some international tourists in July and August. However, borders did not reopen in time and there were virtually no tourists visiting CAREC countries from June to August.

More borders have partially reopened, with many restrictions remaining in place. Demand is limited and CAREC residents are generally only traveling for essential reasons. Therefore, international passenger traffic in CAREC will remain at very low levels in the fourth quarter of 2020 although there will be some improvement compared to the second and third quarters.

This study does not project CAREC traffic for 2021 or beyond. It is too early to make accurate predictions as there are a lot of unknown variables. However, there is an opportunity for CAREC to recover faster in 2021 than the global average. How this can be achieved is discussed later in this study.

\section{A. CAREC Impact: 40 Million Fewer Airline Passengers in 2020}

Prior to the pandemic, the CAREC aviation market (excluding the PRC) consisted of nearly 60 million passengers annually. This represents about 1.3\% of global passenger traffic and includes both local and foreign airlines.

The largest aviation market in CAREC is Pakistan, which accounts for a third of all passenger traffic in CAREC. This is not surprising given that Pakistan is by far the most populated CAREC country, although the size of Pakistan's air transport sector is very small given its large population (over 200 million).

Kazakhstan is the second-largest aviation market in CAREC, accounting for a fifth of all passenger traffic. Pakistan and Kazakhstan are the only CAREC countries with sizable domestic air transport markets. Combined, they account for nearly three-quarters of all domestic passenger traffic in CAREC. 
Azerbaijan, Georgia, and Uzbekistan have similarly sized aviation markets, each accounting for about 9\% of total CAREC passenger traffic. The remaining five CAREC countries-Afghanistan, the Kyrgyz Republic, Mongolia, Tajikistan, and Turkmenistan - have smaller markets that each account for between 3\% and 5\% of the total CAREC air transport market.

This study projects that CAREC countries will experience a passenger traffic reduction of $54 \%-81 \%$ in 2020 . Countries relying heavily on international traffic and particularly international tourism, will have a bigger decline than countries with bigger domestic markets and smaller tourism industries.

Kazakhstan and Pakistan have the largest domestic markets and therefore are proportionately less impacted.

Afghanistan and Turkmenistan have the smallest tourism sectors in CAREC and the size of their domestic markets are relatively large compared to their international markets. Therefore, they are also proportionately less impacted.

Georgia, Tajikistan, and Uzbekistan are proportionately the most impacted. Georgia and Tajikistan have virtually no domestic air travel. Uzbekistan has a small domestic market that relies heavily on international visitors.

While the level of impact varies by country, all CAREC countries have been significantly impacted by COVID-19. The overall 68\% decline in passenger traffic projected by this study for 2020 equates to 40 million fewer passengers than 2019 (see Table 1). Such a significant reduction has a huge impact on CAREC's aviation sector as well as the overall economy.

This forecast represents the most likely scenario as of October 2020. If there are significant new waves of COVID-19 cases in the fourth quarter, a slightly greater reduction in traffic for the full year is possible.

Table 1: 2019 Passenger Traffic for CAREC Countries and 2020 Projections (millions)

\begin{tabular}{|l|c|c|c|c|c|c|c|} 
Country & $\begin{array}{c}\text { Domestic } \\
\mathbf{2 0 1 9}\end{array}$ & $\begin{array}{c}\text { International } \\
\mathbf{2 0 1 9}\end{array}$ & $\begin{array}{c}\text { Total } \\
\mathbf{2 0 1 9}\end{array}$ & $\begin{array}{c}\text { Domestic } \\
\mathbf{2 0 2 0} \text { est }\end{array}$ & $\begin{array}{c}\text { International } \\
\mathbf{2 0 2 0} \text { est }\end{array}$ & $\begin{array}{c}\text { Total } \\
\mathbf{2 0 2 0} \text { est }\end{array}$ & $\begin{array}{c}\text { Y-o-Y } \\
\text { drop }\end{array}$ \\
\hline Afghanistan & $\mathbf{0 . 7}$ & $\mathbf{1 . 5}$ & $\mathbf{2 . 2}$ & 0.4 & 0.4 & 0.8 & $64 \%$ \\
\hline Azerbaijan & 0.6 & 4.4 & 5 & 0.3 & 0.9 & 1.2 & $76 \%$ \\
\hline Georgia & $\ldots$ & 5.2 & 5.2 & $\ldots$ & 1.0 & 1.0 & $81 \%$ \\
\hline Kazakhstan & 5.4 & 6.3 & 11.7 & 4.2 & 1.2 & 5.4 & $54 \%$ \\
\hline Kyrgyz Republic & 0.6 & 2.5 & 3.1 & 0.3 & 0.5 & 0.8 & $74 \%$ \\
\hline Mongolia & 0.4 & 1.2 & 1.6 & 0.4 & 0.2 & 0.6 & $63 \%$ \\
\hline Pakistan & 6.0 & 14.0 & 20.0 & 3.4 & 2.9 & 6.3 & $69 \%$ \\
\hline Tajikistan & $\ldots$ & 2.1 & 2.1 & $\ldots$ & 0.4 & 0.4 & $81 \%$ \\
\hline Turkmenistan & 1.3 & 0.9 & 2.2 & 0.6 & 0.2 & 0.8 & $64 \%$ \\
\hline Uzbekistan & 0.7 & 4.7 & 5.4 & 0.3 & 0.9 & 1.2 & $78 \%$ \\
\hline TOTAL & 15.7 & 42.8 & 58.5 & 9.9 & 8.6 & 18.5 & $68 \%$ \\
\hline
\end{tabular}

$\ldots$... data not available, $\mathrm{CAREC}=$ Central Asia Regional Economic Cooperation, est $=$ estimate, $\mathrm{Y}$-o-Y $=$ year-on-year. Notes:

Georgia and Tajikistan domestic markets have less than 100,000 annual passengers.

Afghanistan and Turkmenistan 2019 figures are estimated based on seat capacity.

Uzbekistan 2019 figures are estimated based on seat capacity and Tashkent traffic.

Pakistan 2019 figures are based on Pakistan fiscal year ending June. All other 2019 figures are based on calendar year.

Source: Author. 


\section{B. CAREC Impact: 46 Million Fewer Airport Passengers in 2020}

For CAREC airports, the projected reduction is 46 million passengers. The higher figure is due to each domestic passenger being counted twice (for embarking and disembarking).

In 2019, airport traffic in CAREC was 74 million. This study projects that due to COVID-19, CAREC airports will handle a combined 28 million passengers in 2020.

This study projects a 62\% decline in airport passenger traffic compared to 2019 (see Table 2). This reduction is less than the $68 \%$ decline for airline passenger traffic due to the higher emphasis on the less impacted domestic market.

Table 2: 2019 Airport Traffic for CAREC Countries and 2020 Projections (millions)

\begin{tabular}{|l|c|c|c|c|c|} 
& $\begin{array}{c}\text { Domestic } \\
\text { Country }\end{array}$ & $\begin{array}{c}\text { International } \\
\mathbf{2 0 1 9}\end{array}$ & $\begin{array}{c}\text { Total } \\
\mathbf{2 0 1 9}\end{array}$ & $\begin{array}{c}\text { Total } \\
\text { 2020 estimated }\end{array}$ & $\begin{array}{c}\text { Y-o-Y } \\
\text { Drop }\end{array}$ \\
\hline Afghanistan & 1.4 & 1.5 & 2.9 & 1.2 & $59 \%$ \\
\hline Azerbaijan & 1.2 & 4.4 & 5.6 & 1.5 & $73 \%$ \\
\hline Georgia & $\ldots$ & 5.2 & 5.2 & 1.0 & $81 \%$ \\
\hline Kazakhstan & 10.7 & 6.3 & 17.0 & 9.6 & $44 \%$ \\
\hline Kyrgyz Republic & 1.2 & 2.5 & 3.7 & 1.1 & $70 \%$ \\
\hline Mongolia & 0.9 & 1.2 & 2.1 & 1.0 & $52 \%$ \\
\hline Pakistan & 12.0 & 14.0 & 26.0 & 9.7 & $63 \%$ \\
\hline Tajikistan & $\ldots$ & 2.1 & 2.1 & 0.4 & $81 \%$ \\
\hline Turkmenistan & 2.6 & 0.9 & 3.5 & 1.4 & $60 \%$ \\
\hline Uzbekistan & 1.4 & 4.7 & 6.1 & 7.5 & $75 \%$ \\
\hline TOTAL & 30.4 & 42.8 & 74.2 & 28.4 & $62 \%$ \\
\hline
\end{tabular}

$\ldots$ = data not available, $\mathrm{CAREC}=$ Central Asia Regional Economic Cooperation, $\mathrm{Y}-\mathrm{o}-\mathrm{Y}=$ year-on-year.

Notes:

Georgia and Tajikistan have limited domestic markets.

Afghanistan and Turkmenistan 2019 figures are estimated based on seat capacity.

Uzbekistan 2019 figures are estimated based on seat capacity and Tashkent traffic.

Pakistan 2019 figures are based on Pakistan fiscal year ending June. All other 2019 figures are based on calendar year.

Source: Author.

Almaty overtook Karachi in 2019 to become the largest airport in CAREC. Two other airports in the main two markets of Kazakhstan and Pakistan, Nur-Sultan and Islamabad, are the third- and fourth-largest airports in CAREC.

Almaty, Karachi, Nur-Sultan, and Islamabad are the only airports in CAREC with over 5 million annual passengers (based on passenger traffic prior to the pandemic). There are another three airports with over 4 million passengers annually-Baku, Tashkent, and Lahore. Tbilisi is the eighth-largest airport in CAREC with 3.7 million passengers handled in 2019.

Prior to the pandemic, there were 14 airports in CAREC with more than 1 million passengers annually. The other six airports with at least 1 million passengers are Ashgabat, Kabul, Bishkek, Ulaanbaatar, Dushanbe, and Peshawar. Ashgabat and Kabul are not listed in Table 3 as they do not report passenger traffic; they both are slightly smaller than that of Bishkek but larger than that of Ulaanbaatar. 
Table 3: 2019 Passenger Traffic for Leading Airports in CAREC (million)

\begin{tabular}{|l|c|c|c|c|}
\hline Airport & Country & Domestic & International & Total \\
\hline Almaty & Kazakhstan & 3.4 & 3.0 & 6.4 \\
\hline Karachi & Pakistan & 2.5 & 3.7 & 6.2 \\
\hline Nur-Sultan & Kazakhstan & 3.2 & 1.8 & 5.1 \\
\hline Islamabad & Pakistan & 1.4 & 3.7 & 5.1 \\
\hline Baku & Azerbaijan & 0.6 & 4.1 & 4.7 \\
\hline Tashkent & Uzbekistan & 0.6 & 3.9 & 4.5 \\
\hline Lahore & Pakistan & 1.0 & 3.5 & 4.5 \\
\hline Tbilisi & Georgia & $\ldots$ & 3.7 & 3.7 \\
\hline Bishkek & Kyrgyz Republic & 0.6 & 1.6 & 2.2 \\
\hline Ulaanbaatar & Mongolia & 0.4 & 1.2 & 1.6 \\
\hline Dushanbe & Tajikistan & $\ldots$ & 1.4 & 1.4 \\
\hline Peshawar & Pakistan & 0.2 & 1.2 & 1.4 \\
\hline TOTAL & & 13.9 & 32.8 & 46.8 \\
\hline
\end{tabular}

$\ldots=$ data not available, $\mathrm{CAREC}=$ Central Asia Regional Economic Cooperation.

Notes:

Dushanbe and Tbilisi have limited domestic flights and do not report domestic traffic.

Tashkent's domestic and international breakdown is estimated.

Pakistan data is for fiscal year ending June 2019; all other data is for calendar year ending December 2019.

Source: Author.

The top 14 airports in CAREC handled nearly 51 million passengers in 2019 (includes 46.8 million passengers for the 12 airports listed in Table 3 and an estimated 4 million passengers for Ashgabat and Kabul combined). This represents nearly $70 \%$ of total airport traffic in CAREC, including $52 \%$ of total domestic traffic and $82 \%$ of total international traffic. About 40 other airports in CAREC have scheduled international services but these are small airports.

Almaty, Nur-Sultan, Tashkent, and Ulaanbaatar were the only major CAREC airports to achieve double-digit passenger growth in 2019.

Tbilisi has been the fastest growing major CAREC airport from 2009-2019, increasing passenger traffic more than fivefold from only 700,000 in 2009 to 3.7 million in 2019. However, Tbilisi's traffic declined by $3 \%$ in 2019 as it was impacted by a suspension of services to the Russian Federation.

Nur-Sultan is the second fastest growing of the main CAREC airports over the same period, increasing passenger traffic nearly fourfold from 1.3 million in 2009 to 5.1 million in 2019.

Nur-Sultan has emerged over the same decade as a hub for CAREC with services to seven destinations in other CAREC countries (excluding the PRC) prior to the pandemic. Almaty is also a hub with services to six destinations in other CAREC countries. Tashkent is a smaller hub in terms of overall passenger volumes but has eight destinations to other CAREC countries, giving it the distinction of having the most CAREC connections.

Kazakhstan has more transit traffic (passengers connecting from one flight to another without leaving the airport) than any other CAREC country. Kazakhstan had about 1 million transit passengers annually prior to the pandemic while Uzbekistan had about 500,000. Most of this traffic consists of passengers that are not heading to or from other CAREC countries; primarily it is traffic from East Asia or India to Europe (including the Russian Federation). 
Figure 1: Tbilisi Passenger Traffic: 2006-2019

Total Passengers (thousands)

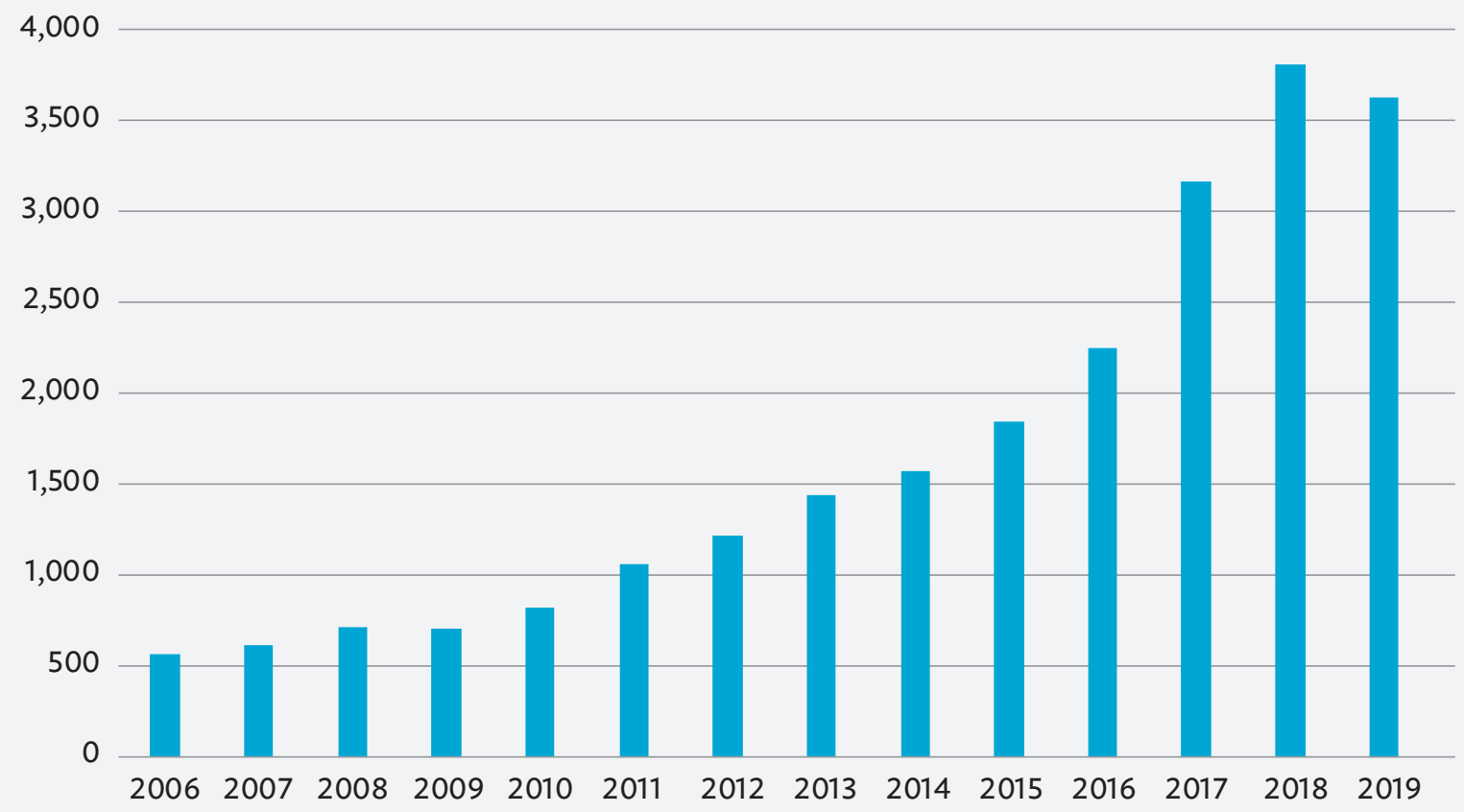

Source: Georgian Civil Aviation Agency.

Figure 2: Nur-Sultan Passenger Traffic: 2006-2019

Total passengers (thousands)

6,000

5,000

4,000

3,000

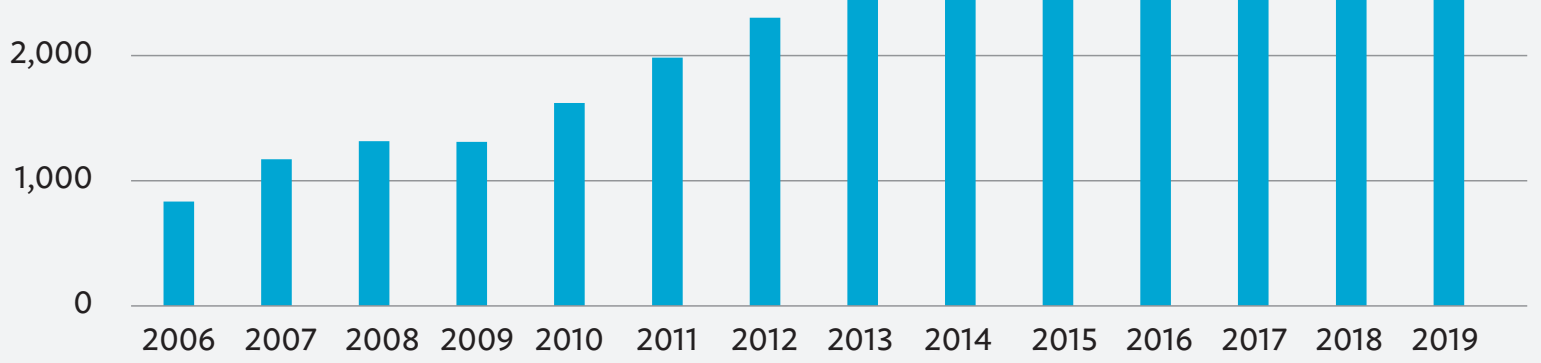

Source: Nur-Sultan Nazarbayev International Airport. 
Azerbaijan, Pakistan, and Turkmenistan also handle a small amount of transit traffic. Overall CAREC (excluding the PRC) has about 2 million international transit passengers annually. This represents about $5 \%$ of total international passenger traffic in CAREC - a small figure compared to other regions, particularly the Gulf, which have large airports that rely primarily on transit traffic.

There is an opportunity for CAREC countries to capture more transit traffic in future. However, transit traffic at CAREC airports will decline significantly in 2020 due to the global drop in international traffic. CAREC airports will likely handle less than 500,000 international transit passengers in 2020.

\section{CAREC Impact: \$7 Billion Reduction in Passenger Revenues}

Each transit passenger is counted twice in the CAREC traffic figures as transit passengers need to take two flights to reach their final destination. However, transit passengers are not counted at all in origin and destination traffic unless they are heading to or from a CAREC country, in which case they are counted once.

In 2018, there were just over 50 million origin and destination passengers in CAREC, according to data from the International Air Transport Association (IATA). ${ }^{2}$ Pakistan is by far the largest market, accounting for 38\% of all CAREC origin and destination traffic. Kazakhstan is the second largest market but its share of origin and destination traffic is less than its share of total traffic as Kazakhstan has more transit traffic than any other CAREC country.

Table 4: Origin and Destination Passenger Traffic for CAREC Countries, 2018 (millions)

\begin{tabular}{|l|c|c|}
\multicolumn{1}{|c|}{ Country } & $\mathbf{2 0 1 8}$ & Growth Compared to 2017 \\
\hline Afghanistan & 2.101 & $-1 \%$ \\
\hline Azerbaijan & 3.894 & $+10 \%$ \\
\hline Georgia & 4.773 & $+29 \%$ \\
\hline Kazakhstan & 8.155 & $+1 \%$ \\
\hline Kyrgyz Republic & 2.594 & $-7 \%$ \\
\hline Mongolia & 1.423 & $+14 \%$ \\
\hline Pakistan & 19.129 & $-1 \%$ \\
\hline Tajikistan & 2.064 & $+1 \%$ \\
\hline Turkmenistan & 1.929 & $-7 \%$ \\
\hline Uzbekistan & 4.086 & $+22 \%$ \\
\hline TOTAL & 50.148 & \\
\hline
\end{tabular}

CAREC $=$ Central Asia Regional Economic Cooperation

Note:

Mongolia figure is total passenger traffic as figure from the International Air Transport Association is not available.

However, this figure should be close to origin and destination traffic given there is virtually no transit traffic in Mongolia. Source: International Air Transport Association.

This study projects a 62\% decline in origin and destination traffic compared to both 2018 and estimated 2019 levels, which is the equivalent of 31 million passengers. IATA is now expecting an over $60 \%$ decline in global origin and destination passenger traffic for 2020 as well as an over $60 \%$ decline in passenger revenues. 
In April, IATA projected a 50\% decline in origin and destination passenger traffic, including a 52\% decline for Pakistan, resulting in a decline for Pakistan of 9.87 million fewer origin and destination passengers. At the same time, IATA also projected a $\$ 1.83$ billion decline in passenger revenues for Pakistan. ${ }^{3}$ IATA has not updated these figures and did not include any other CAREC country in its breakdown by country.

For 2019, IATA reported global passenger revenues were $\$ 612$ billion. This study estimates that CAREC's portion of this was approximately $\$ 10$ billion (based on CAREC's portion of total traffic and adjusted to reflect higher average fares for CAREC given relative small size of domestic market and low market share from low-cost airlines). This study estimates airline revenues in CAREC will decline to only $\$ 3$ billion in 2020.

\section{CAREC Impact: 1 Million Jobs At Risk (IATA methodology)}

IATA also stated in April that 259,400 jobs in Pakistan are at risk as a result of the expected decline in passenger traffic. IATA has not provided jobs at risk projections for other CAREC countries but using the IATA methodology, this study estimates that 1 million travel and tourism jobs are at risk in CAREC.

Globally, IATA estimates there are 65.5 million jobs in aviation or dependent on aviation. This includes 2.7 million jobs at airlines and nearly 63 million jobs at other types of companies in the aviation sector (such as airport jobs) as well in other segments of the travel and tourism industry. IATA warned in April that about 25 million of the total 65.5 million aviation-dependent jobs are at risk due to the decline in passenger traffic. As of October, IATA had not updated this figure.

This study estimates that 1.5 million jobs of the 65.5 million global jobs are in CAREC countries and 1 million are at risk. Pakistan has the most jobs at risk, followed by Georgia. Azerbaijan, Mongolia, Kazakhstan, and Uzbekistan have a roughly similar number of jobs at risk. Afghanistan, the Kyrgyz Republic and Turkmenistan have the least number of impacted jobs.

The number of jobs in travel (includes aviation) and tourism can vary significantly by country depending on popularity as a tourist destination and workforce efficiency. For example, Pakistan and some other CAREC countries have a disproportionately high level of airline and aviation employees given the size of their air transport markets due to inefficiencies. Some CAREC countries such as Azerbaijan, Mongolia, Uzbekistan, and particularly Georgia have big tourism industries compared to their overall economies.

The number of jobs in travel and tourism also vary depending on the methodology used. Based on World Travel and Tourism Council (WTTC) data, there were 330 million travel and tourism jobs globally in 2019. The WTTC projects that $60 \%$ of these jobs, or 197 million, are at risk due to COVID-19. The WTTC last updated this figure in June, when it also stated that international tourist arrivals could drop by up to $73 \%$ in $2020 .{ }^{4}$

The World Tourism Organization (UNWTO) has stated that 100 million-120 million travel and tourism jobs are at risk due to the pandemic. ${ }^{5}$ UNWTO's figures have not been updated since May.

IATA. 2020. COVID-19 Impact on Asia Pacific Aviation Worsens, 24 April. https://www.iata.org/en/pressroom/pr/2020-04-24-01/.

WTTC. 2020. More than 197 Million Travel and Tourism jobs will be lost due to prolonged travel restrictions, $10 \mathrm{June}$. https://wttc.org/News-Article/ More-than-197m-Travel-Tourism-jobs-will-be-lost-due-to-prolonged-travel-restrictions.

5 UNWTO. 2020. Impact Assessment of the COVID-19 Outbreak on International Tourism. 9 March (updated in May). https://www.unwto. org/impact-assessment-of-the-covid-19-outbreak-on-international-tourism\#: :text=In\%20an\%20unprecedented\%20blow\%20to,they\%20 were\%20a\%20year\%20ago.\&text=This\%20translates\%20into\%20a\%20loss,USD\%2080\%20billion\%20in\%20receipts. 
WTTC data indicates that in 2018 there were over 6.2 million travel and tourism jobs in CAREC excluding Afghanistan and Turkmenistan. Data for Afghanistan and Turkmenistan is not available but these are very small markets with limited tourism. Afghanistan and Turkmenistan combined likely have less than 100,000 travel and tourism jobs.

Table 5: Travel and Tourism Jobs in CAREC Countries, 2018

\begin{tabular}{|l|c|c|}
\hline Country & Number of Jobs & \% of Total Employment \\
\hline Azerbaijan & 378,000 & 7.7 \\
\hline Georgia & 488,200 & 27.7 \\
\hline Kazakhstan & 429,800 & 4.9 \\
\hline Kyrgyz Republic & 209,100 & 8.5 \\
\hline Mongolia & 88,700 & 7.6 \\
\hline Pakistan & $3,881,900$ & 6.2 \\
\hline Tajikistan & 164,100 & 6.6 \\
\hline Uzbekistan & 601,700 & 4.6 \\
\hline TOTAL & $6,241,500$ & \\
\hline
\end{tabular}

CAREC $=$ Central Asia Regional Economic Cooperation.

Source: World Travel and Tourism Council.

WTTC employment data for CAREC countries is significantly higher than figures provided by some of the countries and other data sources. WTTC uses a different methodology for calculating jobs and often estimates employment figures based on tourism expenditures. However, the data is still useful for comparison purposes, particularly given that several CAREC countries do not provide travel and tourism employment data.

Based on the WTTC estimates for global job losses and the proportion of total travel and tourism jobs that are in CAREC countries, there are about 3.7 million jobs at risk in CAREC. However, this figure seems too high given the other data sources.

Conservatively, 1 million jobs are at risk. Many of these jobs should return over the next few years as international tourism recovers. However, even the temporary loss of 1 million jobs will have a profound impact on the overall CAREC economy.

\section{E. CAREC Impact: \$11 Billion Reduction in International Visitor Spending, \$27 Billion Reduction in Travel and Tourism Contribution to Gross Domestic Product}

Travel (including aviation) and tourism are important components of the CAREC economy. Travel and tourism accounted for approximately 5\% of CAREC's combined gross domestic product (GDP) (excluding the PRC) prior to the pandemic.

There are several different ways to measure economic contribution. Based on WTTC data for the contribution of travel and tourism to GDP, the main eight CAREC tourism markets generated a combined \$38.2 billion in 2019. Based on WTTC figures for international visitor spending, the same eight countries generated \$11.9 billion. WTTC does not report data for Afghanistan and Turkmenistan. 
Georgia has the highest international visitor spending but the third- highest overall travel and tourism spending after Pakistan and Kazakhstan. This is due to Georgia's relatively small domestic tourism market compared to the much larger overall countries of Kazakhstan and Pakistan.

Of all CAREC countries, Georgia relies the most on travel and tourism, with travel and tourism accounting for an estimated $26 \%$ of GDP in 2019 . No other country in CAREC is above the $10 \%$ global average for travel and tourism contribution to GDP. Georgia is one of the top 25 countries globally for travel and tourism portion of GDP. (Most of the other top 25 countries globally are small island countries with an even higher portion of travel and tourism GDP to total GDP than Georgia.)

In 2019, international visitor spending accounted for 39\% of Georgia's total exports. The Kyrgyz Republic, Tajikistan, and Uzbekistan also have relatively high international visitor spend to total export ratios, indicating a high reliance on international tourism. These countries are therefore proportionally more impacted by the decline in international tourism in 2020 although the dollar value impact is relatively small in the Kyrgyz Republic and particularly Tajikistan, given these are small economies overall.

Table 6: Travel and Tourism Contribution to Gross Domestic Product for CAREC Countries in 2019

\begin{tabular}{|c|c|c|c|c|}
\hline Country & $\begin{array}{l}\text { Travel and Tourism GDP } \\
\text { (\$ million) }\end{array}$ & $\%$ of GDP & $\begin{array}{l}\text { International Visitor Spend } \\
(\$ \text { million })\end{array}$ & $\begin{array}{l}\% \text { of Total } \\
\text { Exports }\end{array}$ \\
\hline Azerbaijan & $3,539.2$ & 7.2 & $1,727.2$ & 6.5 \\
\hline Georgia & $4,487.9$ & 26.3 & $3,578.1$ & 39.0 \\
\hline Kazakhstan & $8,866.1$ & 5.2 & $2,883.5$ & 4.1 \\
\hline Kyrgyz Republic & 722.5 & 8.3 & 515.1 & 18.6 \\
\hline Mongolia & 989.2 & 7.2 & 605.5 & 6.8 \\
\hline Pakistan & $16,576.5$ & 5.9 & 852.2 & 3.1 \\
\hline Tajikistan & 503.7 & 6.4 & 165.3 & 28.4 \\
\hline Uzbekistan & $2,473.5$ & 4.5 & $1,550.9$ & 21.1 \\
\hline TOTAL & $38,158.6$ & & $11,877.8$ & \\
\hline
\end{tabular}

CAREC = Central Asia Regional Economic Cooperation .

Source: World Travel and Tourism Council.

The World Bank has similar figures for international visitor spending, which is often referred to as international tourist receipts. The World Bank includes Afghanistan and Turkmenistan in its data, providing a more complete picture of CAREC overall. The latest available World Bank data is for 2018. The World Bank mainly relies on UNWTO for this data.

Table 7: International Travel and Tourism Contribution for CAREC Countries in 2018

\begin{tabular}{|l|c|c|c|c|}
\multicolumn{1}{c|}{$\begin{array}{c}\text { International Tourism Receipts } \\
\text { (\$ million) }\end{array}$} & $\begin{array}{c}\text { \% of } \\
\text { GDP }\end{array}$ & $\begin{array}{c}\text { Total GDP } \\
\text { (\$ million) }\end{array}$ \\
\hline Afghanistan & 50 & 3.1 & 0.3 & 19,363 \\
\hline Azerbaijan & 2,830 & 11.1 & 6.0 & 46,940 \\
\hline Georgia & 3,518 & 39.5 & 20.0 & 17,600 \\
\hline Kazakhstan & 2,651 & 3.9 & 1.5 & 179,340 \\
\hline Kyrgyz Republic & 487 & 18.7 & 6.0 & 13,067 \\
\hline Mongolia & 526 & 6.8 & 4.0 & 314,588 \\
\hline Pakistan & 818 & 2.7 & 0.3 & 7,523 \\
\hline Tajikistan & 171 & 15.3 & 2.3 & 40,761 \\
\hline Turkmenistan & 46 & $\ldots$ & 0.1 & 50,500 \\
\hline Uzbekistan & 1,314 & 3.8 & 2.6 & 697,775 \\
\hline TOTAL & 12,411 & 1.8 & \\
\hline
\end{tabular}

... = data not available, $\mathrm{CAREC}=$ Central Asia Regional Economic Cooperation, GDP = gross domestic product.

Source: TCdata360 Indicators, World Bank. 
WTTC stated in June that travel and tourism contribution to global GDP could decline by $62 \%$ or $\$ 5.5$ trillion in 2020. Total contribution of travel and tourism to global GDP amounted to $\$ 8.9$ trillion in 2019 , representing $10.3 \%$ of the global economy.

CAREC (excluding the PRC) accounted for only $0.4 \%$ of global contribution of travel and tourism to global GDP in 2019. This relatively low figure is due to a much lower average contribution to GDP (approximately 5\% compared to the global average of $10 \%$ ).

Based on a $62 \%$ global decline, travel and tourism contribution to GDP in CAREC would decline by about $\$ 25$ billion in 2020. However, CAREC will likely experience a higher than average decline due to a higher than average international visitor spend portion. Global visitor exports amounted to $\$ 1.7$ trillion in 2019 with CAREC accounting for a $0.7 \%$ share.

This study estimates that international visitor spending in CAREC will decline by $85 \%$ in 2020, resulting in a reduction of around \$11 billion compared to 2019.

This study estimates that total travel and tourism contribution to GDP in CAREC will decline by $70 \%$ in 2020 , resulting in a reduction of around $\$ 27$ billion. A higher proportional decline than the global average is projected due to CAREC's higher average reliance on international tourism.

The projected $\$ 27$ billion reduction for 2020 is applied on a base of $\$ 38.5$ billion in 2019 . The $\$ 38.5$ billion is calculated using the WTCC figures for the eight countries plus an estimated $\$ 230$ million for Afghanistan and Turkmenistan.

The figures in this section are approximate as there are different methodologies for calculating travel and tourism contribution to GDP and international tourism receipts. Some countries that report their own data use a different methodology than that of the WTTC.

\section{F. CAREC Impact: 33 Million Fewer Visitor Arrivals in 2020}

Tourism in CAREC has been growing rapidly, helping drive overall economic growth as well as growth in the air transport sector.

There were over 36 million visitors to CAREC countries (excluding the PRC) in 2018 (see Table 8). Data for 2019 is not yet available for all countries but visitor arrivals likely exceeded 40 million based on the growth reported by several of the countries.

Uzbekistan had the fastest visitor growth among CAREC countries in 2019, reporting a $26 \%$ increase to 6.749 million visitor arrivals. Uzbekistan visitor numbers have tripled in 3 years, from only 2.027 million in 2016, driven by liberalization and visa reform.

Azerbaijan visitor numbers grew last year by $11 \%$, Mongolia by $9 \%$, and Georgia by $7 \%$.

Kazakhstan and the Kyrgyz Republic have not reported total visitor arrival numbers yet for 2019 . However, the Kyrgyz Republic reported 6.947 million visitors in 2018 and 7.8 million in the first 11 months of 2019, ensuring a double-digit growth rate for the full year. Kazakhstan reported 8.2 million visitors in the first 9 months of 2019, equaling the amount from the first 9 months of 2018 and therefore likely had flat visitor numbers for the full year. 
Pakistan and Tajikistan also have not yet reported visitor arrival data for 2019. These are smaller markets, reporting 3.2 million and 1 million visitor arrivals, respectively, in 2018.

Afghanistan and Turkmenistan do not report visitor data. They have not typically attracted a significant number of visitors and therefore their exclusion does not significantly distort the overall data. In a video conference to discuss the draft of this report, Turkmenistan tourism officials stated that there were about 15,000 visitors in 2019 based on visitor registrations with travel agencies. Unlike other CAREC countries, Turkmenistan does not count visitors who are in Turkmenistan for meetings, exhibitions, and conferences.

Table 8: Visitor Arrivals for CAREC Countries: 2018 and 2019

(millions)

\begin{tabular}{|l|c|c|c|}
\hline Country & $\mathbf{2 0 1 8}$ & $\mathbf{2 0 1 9}$ & Y-o-Y Growth (\%) \\
\hline Azerbaijan & 2.849 & 3.170 & 11.3 \\
\hline Georgia & 7.203 & 7.726 & 7.3 \\
\hline Kazakhstan & 8.789 & & \\
\hline Kyrgyz Republic & 6.947 & & \\
\hline Mongolia & 0.529 & 0.577 & 9.1 \\
\hline Pakistan & 3.200 & & \\
\hline Tajikistan & 1.035 & & 26.2 \\
\hline Uzbekistan & 5.346 & 6.749 & \\
\hline TOTAL & 35.898 & & \\
\hline
\end{tabular}

CAREC = Central Asia Regional Economic Cooperation, $Y$-o-Y = year-on-year..

Note: Data for 2019 not yet available for some countries.

Source: Author (using data and reports from tourism authorities).

This study projects an $83 \%$ decline in visitor numbers, resulting in a 33 million drop compared to the approximately 40 million visitors in 2019.

Azerbaijan and Mongolia have grown rapidly the last 4 years but Georgia has achieved by far the fastest visitor growth among CAREC countries over the last decade. Georgia had 7.726 million visitors in 2019 compared to only 5 million in 2014, 2 million in 2010, and 1 million in 2007.

Figure 3: Annual Visitors to Georgia, 2006-2019

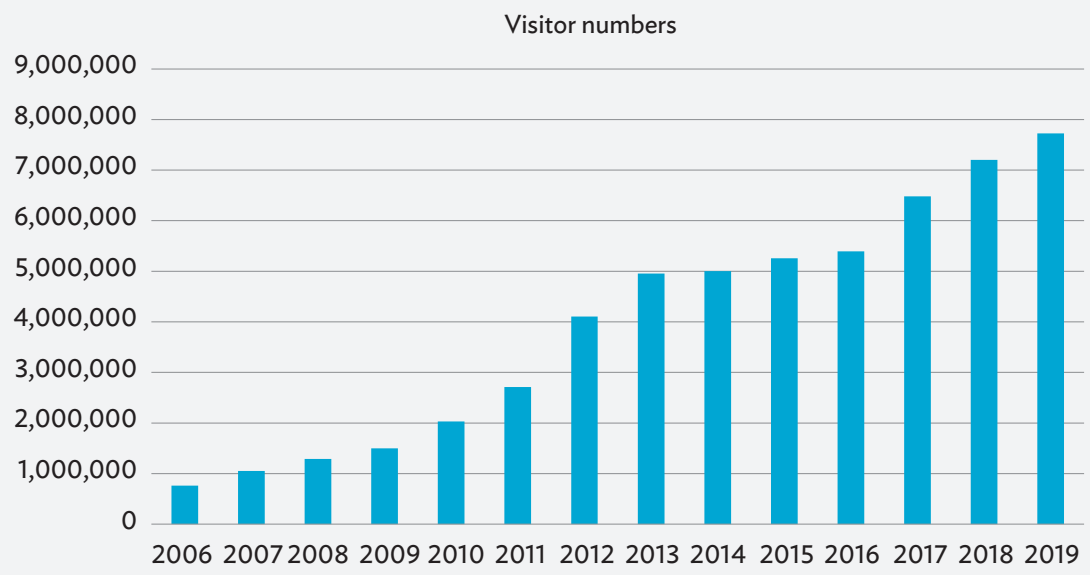

Source: Georgia National Tourism Administration. 


\section{G. CAREC Impact: 5.5 Million Fewer Visitor Arrivals by Air in 2020}

UNWTO is forecasting tourist arrivals globally to decline by $58 \%$ to $78 \%$ in 2020 . Arrivals declined by $22 \%$ in the first quarter of 2020, including a 57\% drop in March as COVID-19 spread globally. ${ }^{6}$

UNWTO initially projected in May a $60 \%-80 \%$ decline in tourist arrivals, stating that the $80 \%$ decline is based on a worst case scenario with borders remaining closed for the entire year and therefore almost all of the visitors for 2020 being confined to the first quarter. The $60 \%$ projection assumed a reopening of borders in the third quarter and visitor numbers starting to recover as early as July.

UNWTO stated in September that tourist arrivals declined in the first half of 2020 by $65 \%$. It slightly updated its projection for the full year, stating tourist arrivals would decline by $58 \%$ to $78 \%$ for the full year. It added that given the trends through August, the decline would be likely closer to 70\%.7 This study projects a higher decline in visitor numbers for CAREC compared to the global average as CAREC countries have not lifted border restrictions as quickly as countries in other regions.

UNWTO and other organizations such as WTTC use different methodologies for counting visitors than most CAREC governments. The UNWTO and WTTC use a definition that only counts a visitor if they stay overnight.

The term "tourist arrival" rather than "visitor" is often used for visitors staying overnight. However, tourist arrivals are not limited to tourists but counts all visitors staying at least one night and less than 1 year. For example, business visitors and students are counted as long as they stay less than a year (if they stay longer than a year they are considered residents).

The availability of overnight visitor data is limited for CAREC countries. Most CAREC countries do not provide a breakdown in their own tourism data of overnight and same day visitors.

For some CAREC countries, UNWTO or WTTC data for overnight visitors seems inaccurate. For example, UNWTO reported 423,000 overnight visitors to the Kyrgyz Republic in 2018 but the National Statistical Committee of the Kyrgyz Republic reported 1.38 million overnight visitors in 2018, growing to 1.78 million in 2019.

UNWTO does not report a breakdown between overnight and same day visitors for Tajikistan and Uzbekistan. It has not reported a breakdown for Kazakhstan since 2014, when there were 4.56 million overnight visitors compared to 1.77 million same day visitors. For Mongolia, the number of overnight visitors reported by UNWTO is the same as what the government reports for total visitors.

For Azerbaijan, the number of overnight visitors reported by UNWTO for 2018 represented $92 \%$ of total visitors, which does not seem accurate given the large number of visitors crossing the land borders with Georgia and Iran. For Georgia, the number of reported overnight visitors was a more realistic $66 \%$ given that $38 \%$ of its visitors are from neighboring Azerbaijan or Armenia.

While some visitors that cross by land stay overnight, most visitors using land crossings are on day trips for shopping or visiting friends and relatives on the other side of the border. Some CAREC borders have large volumes of daytrippers. This type of visitor has less impact on the economy than visitors staying overnight.

6 UNWTO. 2020. International Tourist Numbers Could Fall 60-80\% in 2020.7 May. https://www.unwto.org/news/covid-19-international-touristnumbers-could-fall-60-80-in-2020

7 UNWTO. 2020. International Tourist Numbers Down 65\% in First Half of 2020. 15 September. https://www.unwto.org/news/international-touristnumbers-down-65-in-first-half-of-2020-unwto-reports. 
The decline in same-day visitors will be less in 2020 than the decline in overnight visitors. When borders reopen, the day trip segment typically recovers faster than overnight visitors. However, there will still be a significant reduction in day visitors (likely over 60\%) given the closure of borders for several months due to COVID-19.

Another important statistic in trying to assess the impact of COVID-19 on the CAREC aviation and tourism sectors is visitor numbers by air. Visitors by air is a key statistical indicator for aviation given that in some CAREC countries most passengers are foreigners rather than local residents. It is also an important economic indicator given that visitors by air on average stay longer and spend a lot more than visitors that arrive by land.

Visitors by air data is only available for a few CAREC countries, namely Azerbaijan, Georgia, and the Kyrgyz Republic. Kazakhstan data is also available from 2014 but not in recent years.

Table 9: Visitors by Air for Select CAREC Countries: 2014 and 2018

(thousands)

\begin{tabular}{|l|r|r|r|r|c|}
\hline \multicolumn{1}{|c|}{ Country } & $\mathbf{2 0 1 4}$ & $\mathbf{2 0 1 5}$ & $\mathbf{2 0 1 6}$ & $\mathbf{2 0 1 7}$ & $\mathbf{2 0 1 8}$ \\
\hline Azerbaijan & 1,089 & 969 & 1,165 & 1,152 & 1,184 \\
\hline Georgia & 640 & 738 & 990 & 1,440 & 1,788 \\
\hline Kazakhstan & 874 & & & & \\
\hline Kyrgyz Republic & 388 & 386 & 308 & 408 & 408 \\
\hline
\end{tabular}

CAREC $=$ Central Asia Regional Economic Cooperation .

Source: World Tourism Organization.

For CAREC overall, this study estimates there were 7 million visitors by air in 2019. This segment of traffic therefore accounted for 14 million passengers in 2019, which is around one third of total international passenger traffic in CAREC.

Visitors by air is also referred to as inbound traffic while local residents departing the country by air is known as outbound traffic. The inbound segment will likely decline to around 3 million passengers in 2020, or 1.5 million visitors by air, impacting airlines as well as CAREC's tourism industry.

Of all CAREC countries, Georgia's aviation market is most heavily dependent on inbound traffic. In 2018, visitors accounted for $72 \%$ of Georgia's total passenger traffic. Azerbaijan's aviation market also relies heavily on inbound traffic with visitors accounting for 58\% of total international passenger traffic in 2018.

In all the other CAREC countries, the inbound segment accounts for less than half of total international passengers. In Mongolia the inbound visitor portion of international traffic is only slightly less than 50\% (based on 2019 data from the Government of Mongolia). In the Kyrgyz Republic, visitors accounted for 35\% of total international passenger traffic in 2018.

For Kazakhstan and Uzbekistan, inbound visitors account for roughly $30 \%$ of international traffic. The Kazakhstan figure is an estimate using the 2014 data and the number of visitors in 2018 from countries that typically arrive by air. The Uzbekistan figure is an estimate based on traffic for Uzbekistan Airways, which has previously disclosed the portion of its passengers which are foreigners.

For Afghanistan, Pakistan, Tajikistan, and Turkmenistan, the visitor numbers by air are small. Afghanistan, Tajikistan, and Turkmenistan are small aviation markets overall (around 2 million passengers per annum as previously discussed) and have limited tourism. Pakistan has a large aviation market but of the 3.2 million visitors for 2018 only 17,000 arrived on tourist visa. Pakistan has more significant business visitor volumes that arrive by air but international flights in Pakistan cater mainly to the outbound segment, particularly Pakistanis heading overseas for work. 


\section{CAREC Opportunities}

\section{A. CAREC Opportunity: Growing Domestic and Regional Tourism}

Outbound worker traffic accounts for a large portion of airline revenues throughout CAREC. The Middle East, the Russian Federation, and Turkey are particular popular destinations for migrant workers. For the Russian Federation, some of the traffic travels by land, particularly to cities in Far Eastern region, but air travel is common to the main eastern cities.

Worker traffic is recovering more quickly than tourism traffic as borders reopen. However, the number of migrant workers flying to and from CAREC countries will still decline significantly in 2020.

Outbound tourism traffic is also important. Significantly fewer CAREC residents will travel overseas for holidays in 2020, driving an overall sharp decline in outbound passenger traffic.

During the pandemic, more CAREC residents are taking holidays closer to home due to the restrictions on international travel. This can be seen as an opportunity for several countries to grow domestic tourism, enabling hotels, restaurants, and tourist attractions that normally mainly cater to foreign visitors to recover some of their lost revenues.

Pakistan has the largest domestic tourism market in CAREC with around 50 million domestic trips per annum. This is not surprising given Pakistan's large population and geographic size and relatively low volume of outbound international travelers. Based on 2019 WTTC data, 93\% of Pakistan's travel and tourism spending was on domestic travel.

Domestic tourism is also bigger than international tourism in Kazakhstan and Tajikistan. Based on 2019 WTTC data, domestic accounted for $54 \%$ of total travel and tourism spending in Kazakhstan and $64 \%$ in Tajikistan. Kazakhstan reported 5 million domestic tourists for the first 9 months of 2019.

Domestic tourism is also prevalent in other CAREC countries but international tourism is generally bigger in terms of revenue. Based on 2019 WTTC data, domestic accounted for 43\% of travel and tourism spending in Azerbaijan, 35\% in the Kyrgyz Republic, 31\% in Mongolia, 30\% in Uzbekistan and 22\% in Georgia. Data is not available for Afghanistan and Turkmenistan.

The low figure for Georgia reflects its small population and high number of international visitors. Georgia still has a sizable domestic market, which reopened in June and is generating some revenues for the battered tourism sector. Batumi was a particularly popular holiday spot for Tbilisi residents in July and August but overall tourism was still down as Georgia only reopened to a small number of international countries. 
While there was virtually no domestic tourism from late March to the middle of May it has resumed in all CAREC countries. In several CAREC countries, domestic tourism is expected to be close to normal levels in the last few months of 2020.

Domestic tourism will continue to play an important role in 2021 and until the end of the pandemic. Domestic tourism revenues could reach record highs for several CAREC countries in 2021 as restrictions on overseas travel will likely remain and many residents may prefer to holiday closer to home even if border restrictions ease. However, to fully realize the potential of domestic tourism, countries will need to promote domestic holidays and tourism companies will need to adapt to meet the needs of local travelers.

While overall hotel occupancy rates will still be down due to the decline in international tourism, a quick recovery in domestic tourism helps mitigate the impact to the overall tourism sector. Tourism companies (and their employees) that rely mainly on domestic market are less impacted than companies (and their employees) that rely on international visitors. However, some international focused companies should be able to shift focus and attract more domestic visitors.

Aviation will also benefit somewhat from growth in domestic tourism, particularly in the main domestic markets of Kazakhstan and Pakistan. In the other CAREC countries, airlines are not generally used for domestic holidays although there are some opportunities to stimulate domestic demand. Airlines and governments should promote domestic air travel as it will help boost utilization of aircraft and crew that have been impacted by the decline in international travel. All CAREC countries have at least a few domestic routes where air travel is an option although Kazakhstan and Pakistan have the advantage of significantly more domestic routes, including several where air travel is the only practical option given the distances involved.

While some are wary of traveling by air during the pandemic, aircraft are considered relatively safe given their modern hospital grade filters. Buses and trains could be viewed as riskier. Older passenger trains that rumble on for several hours or even days before being serviced are common in CAREC.

Kazakhstan is particularly well positioned to attract domestic air travelers due to low fares and a young population that is eager to travel again. Kazakhstan's domestic market grew rapidly in the second half of 2019 and the first 2 months of 2020 driven by new low-cost airline FlyArystan, which commenced operations in May 2019. Kazakhstan's domestic market has recovered rapidly in recent months and should reach record levels in 2021, surpassing the slightly over 5 million domestic passengers from 2019. Promotional rates for both flights and hotels are already successfully stimulating the budget segment of the market.

\section{Recommendation: CAREC should promote domestic tourism to help facilitate a recovery of the aviation and tourism sectors during a period of much lower international traffic.}

\section{B. CAREC Opportunity: Creating Green Lanes Between CAREC Countries}

There is also an opportunity to promote regional tourism within CAREC in 2021 as an alternative to traveling outside the region, which could remain restrictive or challenging until there is a vaccination.

While CAREC residents frequently cross the border to neighboring countries, particularly those living near a border, these typically are short excursions for shopping, business, or visiting friends and family rather than 
tourism. Most CAREC residents have never fully explored tourism destinations in neighboring CAREC countries. Travel to another CAREC country that does not share a border is even less common.

For example, Mongolia attracted only 18,000 visitors from other CAREC countries (excluding the PRC) in 2019. This includes just over 16,000 residents from Kazakhstan, which is Mongolia's closest CAREC neighbor although they do not share a border. Visitors to Mongolia from the eight other CAREC countries combined totaled less than 1,700, led by 700 from the Kyrgyz Republic.

Mongolia has gained notoriety in recent years as a tourist destination but is not well known among residents in other CAREC countries. This would be an ideal time for CAREC residents to consider visiting Mongolia as its open spaces, pristine countryside, and ecotourism attractions provide a low-risk environment during the pandemic.

Azerbaijan and Georgia have similarly emerged as popular tourist destinations but should be able to attract more visitors from other CAREC countries. While Azerbaijan and Georgia have a lot of traffic between them the number of visitors from other CAREC countries is low, particularly compared to the number of visitors from European countries.

In 2018, Azerbaijan attracted 41,000 visitors from Pakistan; 38,000 visitors from Kazakhstan; 28,000 from Turkmenistan; 18,000 from Uzbekistan; 3,000 from the Kyrgyz Republic; 2,000 from Tajikistan; 1,000 from Afghanistan; and less than 200 from Mongolia. Georgia attracted the same year 59,000 visitors from Kazakhstan; 10,000 from Turkmenistan; 8,000 from Pakistan; 7,000 from the Kyrgyz Republic; 2,000 from Tajikistan; 400 from Afghanistan; and 200 from Mongolia.

Pakistan has the potential to become a large source market for several CAREC countries. Pakistan is by far the most populated CAREC country but there are only around 60,000 Pakistani visitors per annum to all other CAREC countries combined (excluding the PRC).

Azerbaijan is the largest CAREC destination for Pakistan residents with 41,000 visitors in 2018 while Georgia is the second largest with only 8,000 visitors (as mentioned above). Kazakhstan reported only 1,500 Pakistan visitors in 2018 while Tajikistan reported less than 500, and Mongolia less than 300. Data on Pakistan visitors to the other three countries is not available but likely totaled less than 10,000.

Countries in other regions have been establishing green lanes-also known as bubbles or air bridges - with select countries. There are no green lanes yet in CAREC.

While some CAREC countries have started lifting border restrictions, the approach has generally been piecemeal and unilateral. Bilateral green lanes between CAREC countries or a multilateral green lane involving several CAREC countries would help facilitate the resumption of travel within CAREC and the recovery for CAREC's aviation and tourism sectors.

The green lane concept provides an option for countries that have been relatively successful in containing the virus to reopen to each other with certain guidelines or requirements. The requirements for traveling in the green lane vary by country but can include testing negative for COVID-19 prior to travel. There can also be daily limits on the number of travelers.

The focus by CAREC countries so far have been mainly on reopening source markets outside CAREC. For example, when Georgia reopened to international tourism at the end of July it only lifted restrictions for Estonia, France, Germany, Latvia, and Lithuania. 
The external focus is understandable given the biggest source markets for CAREC tourism are outside, particularly Europe and North Asia. However, establishing green lanes with European or North Asian countries is challenging given that European and North Asian countries seem to be initially prioritizing tie-ups within their own regions.

For example, Europe reopened borders this summer but the focus was mainly on the 26 countries within Schengen. It has been difficult for a CAREC country to forge an agreement with any Schengen country as there is no way to control movement within Schengen once a tourist arrives.

Several green lanes are also being established in the Asia and Pacific region. For example, Singapore has already opened green lanes with Brunei Darussalam, the PRC, Indonesia, Japan, Malaysia, and the Republic of Korea. Singapore also has announced an air travel bubble, allowing all types of travelers, with Hong Kong, China.

The initial phase of the international recovery is expected to focus mainly on regional travel with tourists taking short flights rather than long flights. For CAREC, this is an opportunity to promote tourism within CAREC.

With restrictions likely to remain in place for travel from CAREC to many countries outside CAREC, intra-CAREC tourism could flourish. However, the right strategies and policies need to be put in place.

CAREC countries should consider forming their own green lanes, facilitating tourism as well as economic activity. CAREC could potentially be used as a platform for bilateral and multilateral agreements.

The CAREC green lane concept would be for those CAREC countries that are ready to start opening up to work with other like-minded CAREC countries. This could result in several green lanes between CAREC countries by spring 2021, boosting tourism next summer. Promoting intra-CAREC tourism over the next several months is particularly important as international visitor numbers from traditional source markets outside CAREC to likely to remain very low in summer 2021.

The CAREC green lane concept does not preclude CAREC countries also establishing green lanes outside CAREC. The idea is for CAREC countries that are ready to have green lanes with select countries to use CAREC as a platform for establishing green lanes with CAREC.

Travel between all CAREC countries may not be feasible in the initial phase. However, green lanes for all of CAREC could become an objective after a few months.

CAREC countries should also consider establishing visa-free policies to further facilitate travel within CAREC. While visa-free options have increased in recent years, most CAREC countries still require visas from some other CAREC countries.

For example, almost all CAREC countries still require visas for Pakistan residents. As outlined earlier in this section, Pakistan is a large potential source market for other CAREC countries. Green lanes will help but if they are not accompanied with a visa-free travel policy, the impact will be muted and there will likely not be sufficient demand to support direct flights.

Promoting intra-CAREC tourism during these difficult times will help kickstart the aviation and tourism sectors by providing much needed revenue for airlines, hotels, restaurants, and tourist attractions. While the objective would be to facilitate tourism over the next year, there could also be a positive long-term impact as citizens of CAREC countries get more familiar with destinations in other CAREC countries, particularly Silk Road UNESCO heritage sites. 


\section{Recommendation: CAREC countries should consider opening green lanes to facilitate and stimulate travel and tourism within CAREC.} Recommendation: CAREC countries should consider implementing a visa-free policy to further
facilitate travel and tourism within CAREC.

\section{CAREC Opportunity: Improving Air Connectivity within CAREC}

Promoting intra-CAREC tourism would also help boost connectivity within CAREC. Routes within CAREC could potentially be resumed quickly and even expanded if tourism flows increase.

A lack of connectivity has long been a major impediment to travel between CAREC countries. In 2017, when Asian Development Bank (ADB) examined CAREC connectivity as part of an aviation study, there were 31,000 weekly seats between CAREC countries (excluding the PRC).

Capacity within CAREC has since declined further. Total weekly capacity between CAREC countries (excluding the PRC) was only around 14,000 weekly one-way seats in the first 2 months of 2020 or 28,000 weekly return seats.

Table 10: Intra-CAREC One-Way Weekly Seat Capacity: Before COVID-19

\begin{tabular}{|l|r|r|r|r|r|r|r|r|r|r|}
\hline Country & AFG & AZE & GEO & KAZ & KGZ & MON & PAK & TAJ & TKM & UZB \\
\hline Afghanistan & & 0 & 0 & 0 & 0 & 0 & 500 & 300 & 0 & 300 \\
\hline Azerbaijan & 0 & & 1,500 & 1,500 & 0 & 0 & 0 & 0 & 0 & 500 \\
\hline Georgia & 0 & 1,500 & & 1,000 & 0 & 0 & 0 & 0 & 500 & 300 \\
\hline Kazakhstan & 0 & 1,500 & 1,000 & & 1,200 & 200 & 0 & 1,000 & 0 & 3,500 \\
\hline Kyrgyz Republic & 0 & 0 & 0 & 1,200 & & 0 & 0 & 200 & 0 & 500 \\
\hline Mongolia & 0 & 0 & 0 & 200 & 0 & 0 & 0 & 0 & 0 & 0 \\
\hline Pakistan & 500 & 0 & 0 & 0 & 0 & 0 & & 0 & 0 & 300 \\
\hline Tajikistan & 300 & 0 & 0 & 1,000 & 200 & 0 & 0 & & 300 & 500 \\
\hline Turkmenistan & 0 & 0 & 0 & 500 & 0 & 0 & 0 & 300 & & 0 \\
\hline Uzbekistan & 300 & 500 & 300 & 3,500 & 500 & 0 & 300 & 500 & 0 & \\
\hline TOTAL & 1,100 & 3,500 & 2,800 & 8,900 & 1,900 & 200 & 800 & 2,300 & 800 & 5,900 \\
\hline
\end{tabular}

$\mathrm{AFG}=$ Afghanistan, AZE = Azerbaijan, CAREC = Central Asia Regional Economic Cooperation, COVID-19= coronavirus disease, $\mathrm{GEO}=$ Georgia, KAZ = Kazakhstan, KGZ = Kyrgyz Republic, MON = Mongolia, PAK = Pakistan, TAJ = Tajikistan, TKM = Turkmenistan, UZB = Uzbekistan

Notes: Figures are based on Official Airline Guide schedules for first 2 months of 2020.

Seat figures are approximates.

Source: Author.

Prior to COVID-19, only 18 or $44 \%$ of all CAREC country pairs (excluding the PRC) were connected with nonstop flights. The number of country pairs with nonstop services has improved slightly, increasing from 16 in 2017. However, a reduction in frequencies from an already low base has resulted in capacity declines on many country pairs. 
Of the 18 country pairs served prior to the pandemic, only six or one third had at least seven weekly frequencies (equivalent of a daily service). In 2017, eight country pairs had at least seven weekly frequencies.

The lack of nonstop frequencies, makes it difficult to travel around the region for business or leisure. Weekend getaways or 1 day business trips, which are common in other regions such as Europe or Southeast Asia, have been impossible between most CAREC countries due to limited flight frequencies.

Under normal circumstances, it could take a few years to rebuild the limited connectivity between CAREC countries that existed pre-COVID 19, setting back by several years CAREC aspirations for improving connectivity. However, it could be feasible to reestablish in 2021 the air connections that existed before COVID-19 if green lanes between CAREC countries are implemented and if CAREC promotes intra-CAREC tourism.

Green lanes would stimulate demand for air travel within CAREC, enabling airlines to resume intra-CAREC routes quicker than routes with countries outside CAREC. On some routes, a surge in air traffic could even result in more flights than previously.

Table 11 shows is a list of routes that could potentially support daily services if supported by green lanes and stimulated with promotions. Most of these routes were only operated by one airline prior to the pandemic but could potentially support more airlines as frequencies are added.

Table 11: Examples of Underserved Intra-CAREC Routes that Can Support More Frequencies

\begin{tabular}{|c|c|c|c|}
\hline Route & $\begin{array}{l}\text { Frequencies prior } \\
\text { to COVID-19 }\end{array}$ & $\begin{array}{l}\text { Potential } \\
\text { Frequencies }\end{array}$ & Operating Airline(s) Prior to COVID-19 \\
\hline Aktau-Tbilisi & 5 per week & 1 daily & SCAT Airlines \\
\hline Almaty-Ashgabat & 3 per week & 1 daily & Turkmenistan Airlines \\
\hline Almaty-Baku & 5 per week & 1 daily & Air Astana, Buta Airways \\
\hline Baku-Nur-Sultan & 4 per week & 1 daily & Air Astana \\
\hline Baku-Tashkent & 5 per week & 1 daily & Buta Airways, Uzbekistan Airways \\
\hline Batumi-Nur-Sultan & 2 per week & 1 daily & SCAT Airlines \\
\hline Bishkek-Dushanbe & 1 per week & 1 daily & Somon Air \\
\hline Bishkek-Nur-Sultan & 3 per week & 1 daily & Air Astana \\
\hline Dushanbe-Tashkent & 3 per week & 1 daily & Somon Air, Uzbekistan Airways \\
\hline Kabul-Tbilisi & 2 per week & 1 daily & Kam Air \\
\hline Lahore-Tashkent & 2 per week & 1 daily & Uzbekistan Airways \\
\hline Nur-Sultan-Ulaanbaatar & 2 per week & 1 daily & SCAT Airlines \\
\hline Tashkent-Tbilisi & 2 per week & 1 daily & Uzbekistan Airways \\
\hline
\end{tabular}

CAREC $=$ Central Asia Regional Economic Cooperation, COVID-19 = coronavirus disease.

Source: Author.

Governments should consider supporting the resumption of international routes within CAREC that have been suspended due to COVID-19 by implementing various initiatives and schemes. For example, waiving or reducing taxes and fees would help stimulate demand as airlines would be able to reduce the total price of a ticket (potentially by over $50 \%$ ) and offer short international flights at all-inclusive fares similar to domestic flights. As outlined in the last section, implementing visa-free travel where there are still restrictions would also help facilitate travel between CAREC countries. 
CAREC countries should consider similar schemes as well as incentives to support the launch of new routes within CAREC. New route incentives are typical around the world but have not been used effectively to facilitate new air services within CAREC.

Several new routes connecting major CAREC cities with tourist destinations in other CAREC countries could be stimulated with a combination of green lanes, the right policies, and promotions. Bukhara and Samarkand in Uzbekistan, Osh in the Kyrgyz Republic, and Batumi in Georgia are examples of tourist destinations that could potentially attract several routes from CAREC countries. As highlighted in the last section, there are particularly new route opportunities from Pakistan, which prior to the pandemic had only two routes to other CAREC countries.

Table 12 shows is a sampling of 20 potential new routes within CAREC that could potentially be launched in 2021 by establishing green lanes and with the right policies, incentives, and promotions. It will not be realistic to quickly launch so many routes but those that do not get the green light in 2021 could potentially be considered over the next few years as the market recovers further and grows.

Table 12: Examples of Unserved Routes Within CAREC

\begin{tabular}{|l|c|}
\hline Route & Initial Frequency \\
\hline Almaty-Batumi & 3 per week \\
\hline Almaty-Bukhara & 2 per week \\
\hline Almaty-Karachi & 3 per week \\
\hline Almaty-Osh & 3 per week \\
\hline Almaty-Samarkand & 2 per week \\
\hline Almaty-Ulaanbaatar & 2 per week \\
\hline Ashgabat-Baku & 2 per week \\
\hline Baku-Bishkek & 2 per week \\
\hline Baku-Dushanbe & 2 per week \\
\hline Bishkek-Karachi & 2 per week \\
\hline Bishkek-Tbilisi & 3 per week \\
\hline Dushanbe-Tbilisi & 2 per week \\
\hline Kabul-Samarkand & 2 per week \\
\hline Karachi-Osh & 2 per week \\
\hline Karachi-Samarkand & 2 per week \\
\hline Karachi-Tashkent & 3 per week \\
\hline Lahore-Bukhara & 2 per week \\
\hline Lahore-Samarkand & 2 per week \\
\hline Nur-Sultan-Issy Kul & 2 per week \\
\hline Tbilisi-Ulaanbaatar & 2 per week \\
\hline
\end{tabular}

CAREC $=$ Central Asia Regional Economic Cooperation .

Source: Author.

A few weeks after the initial draft of this study was published, including Table 12, Air Astana announced plans to launch in July the first route in this list-Almaty to Batumi. However, the launch had to be scrapped as Georgia did not reopen the border with Kazakhstan. As of October, Georgia had still not lifted border restrictions with Kazakhstan and as a result, Air Astana also has not yet resumed services to Tbilisi.

Hopefully, Almaty-Batumi will be launched in summer 2021 along with several others listed in the table including Almaty-Ulaanbaatar. Mongolia's Hunnu Air stated in late September 2020, after operating a repatriating charter flight to Almaty, that it aims to launch scheduled flights from Ulaanbaatar to Almaty once epidemiological conditions improve. 
With more travel within CAREC during the recovery phase, the building blocks could be put in place for further connectivity improvements over the next few years. This in turn will support growth aspirations for CAREC tourism as visitors from outside CAREC, once they return, will be able to more easily visit multiple countries.

The lack of connectivity within CAREC has made it difficult for tourists to pursue multicountry itineraries and combine Silk Road tourist attractions. Improved air connectivity is essential for CAREC to achieve long-term tourism growth targets. Without better connectivity, CAREC will lose potential tourists from outside the region to other easier to access destinations.

In this respect, better connectivity within CAREC will ultimately lead to improved connectivity to and from CAREC. While CAREC's connectivity with Europe and Asia will initially decline due to COVID-19 there will eventually be an opportunity to start rebuilding connectivity with other regions.

Offering improved connections within the region will help attract more long-haul flights and visitors. Air transport in CAREC could potentially recover faster than air transport globally. Promoting intra-CAREC travel and connectivity could prove to be the first step toward achieving this.

An uptick in intra-CAREC travel would also help drive improved coordination between CAREC tourism authorities and governments. This in turn could lead to improvements in areas that have previously been identified by ADB as impediments to intra-CAREC travel such as visa facilitation and airline partnerships.

To facilitate airline partnerships and tourism growth over the long term, a separate study was completed by ADB at the beginning of August that examines a possible air pass scheme for CAREC. The proposed Silk Road Air Pass, which could further drive improvements in air connectivity within CAREC after the pandemic ends, is now being reviewed by CAREC countries and airlines.

\section{Recommendation: CAREC should promote improved air connectivity between CAREC countries during the pandemic and after this crisis.}

Recommendation: CAREC should consider providing incentives to support the launch of new routes connecting major cities with tourist destinations in other CAREC countries.

\section{CAREC Opportunity: Expand Cargo Capabilities}

Cargo is an important source of revenues for airlines and airports throughout CAREC. The sharp decline in passenger traffic during the pandemic has further increased the importance of cargo and led to some airlines increasing their cargo capacity. This is an opportunity for CAREC's aviation industry to further invest in cargo capabilities, providing a foundation for long-term growth.

Prior to the COVID-19, a majority of air cargo flew in the bellies of passenger aircraft. The steep reduction in passenger flights has led to a significant decrease in overall cargo capacity globally as well as in CAREC. Total air cargo volumes will therefore decline in 2020. IATA has reported double digit monthly reductions in cargo tonne kilometers every month since March.

However, the decline in cargo traffic so far this year is much less than the decline in passenger numbers due to a significant increase in cargo flights. Higher air cargo yields also has helped boost cargo revenues. 
CAREC is fortunate to have a relatively large number of freighters compared to other regions and several cargo airlines. CAREC also boasts several modern air cargo facilities that handle the local freighter fleet and cargo heading to and from the region as well as freighters and transshipment cargo heading between Asia and Europe that stop in CAREC countries.

While global cargo volumes are down in 2020, some CAREC airports have experienced a significant increase in cargo flights since the start of the pandemic due to their strategic location. As cargo flights between Asia and Europe has increased more aircraft have been stopping in CAREC countries to refuel and change crews.

Prior to the pandemic, CAREC airports handled around 800,000 tonnes of air cargo. This represents about 1.3\% of global cargo traffic.

Azerbaijan and Pakistan particularly have large cargo markets. Pakistan reported handling 330,350 tonnes of air cargo in the fiscal year ending June 2019 while Azerbaijan handled 206,400 tonnes in calendar 2019.

Kazakhstan is the third-largest cargo market in CAREC with at least 80,000 tonnes handled in 2019 (based on the 69,000 tonnes reported by Almaty and the 11,000 tonnes reported by Nur-Sultan). Uzbekistan is the fourthlargest market with an estimated 70,000 tonnes handled in 2019.

The Kyrgyz Republic (33,000 tonnes in 2018), Georgia (25,000 tonnes in 2019), Mongolia (6,000 tonnes in 2019) and Tajikistan (3,000 tonnes 2019) have much smaller cargo markets. Afghanistan and Turkmenistan are also small cargo market but no traffic data is available.

Azerbaijan reported a more than doubling of air cargo volumes for the first 8 months of 2020 to 277,000 tonnes. During the pandemic, Azerbaijan and neighboring Georgia have both been popular for handling cargo flights with medical equipment heading from the PRC to Europe and the Commonwealth of Indenpendent States.

Air Astana and Uzbekistan Airways have removed seats from 767 passenger aircraft to generate additional cargo capacity. Several airlines have also seen using passenger aircraft to carry cargo by placing cargo on top of seats and in the overhead bins as well as in the belly.

CAREC airports and governments should look at further investing in cargo facilities to help attract more transit cargo and support exports. Cargo is generating critical revenues for airports and airlines during this difficult time. With the right strategies, cargo could become an even bigger revenue generator for CAREC's aviation industry and help stimulate trade.

CAREC governments should also pursue full liberalization of the air cargo market to facilitate air cargo growth during and after the pandemic. Air cargo services generally operate under a more liberal regulatory environment than passenger services-both in CAREC and globally. However, further liberalization would help CAREC countries recover economically and make the movement of goods, including perishable food, easier during the current challenging period.

Recommendation: CAREC should invest in boosting air cargo capabilities, leveraging its strategic location between Asia and Europe and driving increased cargo revenues for the aviation industry during a period of passenger declines.

\section{Recommendation: CAREC should pursue liberalization of the air cargo market now to facilitate air cargo movements during the pandemic and air cargo growth over the next several years.}




\section{E. CAREC Opportunity: Upgrade Airports with Contactless Technologies}

COVID-19 has led to major changes in the air travel experience in order to minimize risk of the virus spreading. Airlines and airports around the world are now accelerating the adoption of new technologies to support contactless travel.

While digitalization was already a major global trend in the aviation industry prior to the pandemic, CAREC was generally behind in implementing new digital technologies and procedures. This crisis provides an opportunity for CAREC to catch up with other regions from a digitalization perspective while also meeting new expectations for contactless air travel.

Many airports in CAREC rely mainly on manual check-in and boarding processes. Significant investments will be required to support new digital and contactless procedures. Capacity constraints also have to be carefully managed in order to meet social distancing requirements, particularly in airport terminals that mainly cater to domestic travel as domestic traffic will recover much faster than international traffic.

Investment by CAREC airlines will also be required to facilitate online or mobile check-in and document checks. Using new technologies, passengers can bypass the check-in desk and drop their bags on a belt without needing to interact with any staff. Contactless security and immigration are also possible with the right investments from airports and governments.

This crisis also presents a potential opportunity for CAREC countries to accelerate airport capacity expansion projects. Several airports in CAREC were congested and operating well above design capacity prior to the pandemic. Construction can be pursued now, using safe distancing measures to protect workers and minimizing disruptions to existing operations given the lower than normal levels of passenger traffic. Airport construction projects would help boost the CAREC economy and create new jobs during this challenging period.

CAREC countries also should consider adopting uniform regulations and standards for air travel during the pandemic. Globally there is a lack of harmonization, which the aviation industry is now trying to address with new guidelines and recommendations for mitigating the risk of virus transmission during the travel process.

CAREC countries should look at adopting the new guidelines and recommendations issued by the International Civil Aviation Organization. By conforming to new global standards, CAREC countries will facilitate the resumption of international travel and eliminate differences in regulations from country to country, which are now creating challenges and confusion for airlines and passengers.

CAREC countries should also consider adopting the recommendations issued by IATA, including the deployment of COVID-19 testing as an alternative to quarantine measures. Airport COVID testing is becoming increasingly common around the world and it is important that CAREC countries and airports also put in place testing programs. 
For several months, the global aviation industry has been trying to support the resumption of air travel through several initiative that facilitate air travel but require uniform adoption by governments. Unfortunately, governments have been very slow to agree on standards for international air travel. While CAREC cannot have much of an influence globally, CAREC can improve the regional situation by advocating all CAREC countries to agree on new standards and regulations, thereby facilitating the resumption of international travel within CAREC.

Recommendation: CAREC should promote contactless air travel and invest in technologies to support digital procedures at airports.

Recommendation: CAREC should adopt uniform standards and regulations for air travel in the COVID-19 environment. 


\section{CAREC Needs}

\section{A. CAREC Need: Government Support for Aviation and Tourism}

CAREC countries should consider providing support packages to help airlines, airports and other aviation industry companies survive a period of significantly reduced revenues.

Government support packages for the aviation industry have become common globally but so far they are limited in number and scope in CAREC.

Airlines in over 60 countries have secured financial support packages from their governments. These packages typically include loans or loan guarantees from government banks. In some cases, governments are providing capital directly, particularly with airlines that are already $100 \%$ government-owned. In other cases, government investment firms are used to back rights issues or increase equity stakes.

The total amount of financial support committed so far is over $\$ 100$ billion with France ( $\$ 8$ billion), Germany ( $\$ 12$ billion), Singapore ( $\$ 10$ billion) and the United States ( $\$ 29$ billion) providing the largest individual packages. The $\$ 100$ billion-figure excludes several countries such as the United Arab Emirates, which have announced financial support packages for airlines without disclosing specific amounts. When including the countries that have not provided specific figures, the total value of government financial support packages for airlines could exceed $\$ 200$ billion.

Both government-owned and privately-owned airlines have benefitted from the government financial support packages globally. In countries where there are both government and privately-owned airlines, it is important to treat both equally although some countries have opted to only support government-owned airlines, creating a potentially uneven playing field. In countries where there are only privately-owned airlines, support is not necessarily provided to all airlines but it is also important to treat all airlines equally. In some of these countries not all airlines apply for government loans or not all airlines meet the terms and conditions.

This study estimates that CAREC airlines may need $\$ 2$ billion in financial support to survive this crisis. CAREC countries should consider providing financial support to airlines through soft loans or loan guarantees.

Without this support, several airlines may collapse, resulting in reduced connectivity and higher air fares. This in turn would inhibit a recovery in international tourism and impact the overall economy.

CAREC countries should also keep in mind that their airlines could be at a competitive disadvantage as most of their main foreign airline competitors have been able to secure government financial support. Several CAREC 
airlines already struggle to compete with foreign airlines and there is a risk the gap between CAREC airlines and their generally stronger foreign competitors will widen.

Any financial support provided should have terms and conditions to ensure the capital is used to cover operations, including labor costs, during the pandemic. Loans should be paid back over time under normal commercial terms but with low or no interest. This should not be viewed simply as grants or aid without any requirements for disclosing how the funds are used.

So far it appears that only one airline in CAREC, Uzbekistan Airways, has secured government financial support since the start of the pandemic. However, it is possible other airlines in CAREC countries, particularly government-owned airlines, have secured support without any formal announcements.

Uzbekistan has provided $\$ 50$ million in interest-free grants or loans to Uzbekistan Airways and Uzbekistan airports. Extensions or deferrals on $\$ 120$ million in prior loans was also granted as well as $\$ 6$ million in tax concessions.

The tax concessions are an example of general support for all businesses rather than airline specific financial support. Tax reductions and waivers for companies impacted by COVID-19 is common in CAREC and globally as part of general economic stimulus packages announced by governments.

The two biggest examples of COVID-19 economic stimulus packages in CAREC are Kazakhstan and Pakistan. During the initial few months of the pandemic, Kazakhstan announced packages valued at $\$ 10$ billion while Pakistan announced packages valued at $\$ 5$ billion. However, there are no aviation-specific benefits in these packages.

In Pakistan, the relief provided is aimed mainly at laborers, low-income families, agriculture, medical equipment, and small companies. While some small companies in the aviation and tourism sectors may be eligible for some of the benefits, the value is not significant.

In Kazakhstan, the stimulus measures have focused on creating hundreds of thousands of temporary jobs by launching infrastructure, maintenance, and construction projects. Small companies are eligible for deferrals in loan payments and soft loans. While some of the measures could help companies in the aviation and tourism sectors, the value of benefits are not yet significant.

Several other CAREC countries are providing tax exemptions, soft loans for small businesses, and reduction in utility fees. Companies from all industries, including aviation and tourism, are eligible to receive some of these benefits. However, the value of these benefits for any individual company in tourism and aviation has so far not been that significant.

Some CAREC countries have promised certain benefits to companies in the travel and tourism sectors but have yet to provide them or come up with concrete plans. There is a risk that many companies will go bankrupt by 2021 without government support. Hotels and some airlines are particularly vulnerable.

CAREC's travel and tourism sectors, including aviation, rely on the summer months to generate revenues to cover costs incurred throughout the year. Due to border closures, summer (June-August) 2020 was extremely challenging for CAREC's travel and tourism sectors. Some companies will struggle to remain in business until summer 2021 and travel in summer 2021 is also now expected to be well below 2019 levels. Loans from government banks may be required to avoid mass bankruptcies, which could have a long-term impact on the economy and ability of the travel and tourism sectors to recover. 
Wage subsidies are also common globally as part of general economic stimulus packages. However, this is not a common benefit in CAREC countries.

Wage subsidy or job protection schemes have been implemented since the start of the pandemic in over 50 countries. In most countries, the subsidies constitute a significant benefit in that they cover the majority of wages at impacted companies for employees that are temporarily not working or are working reduced hours. For airlines, often most or all employees have been covered given the huge reduction in flying has led to most employees working less or being temporarily furloughed. Airports and other companies in the aviation industry as well as companies in the tourism sector have similarly benefited from these schemes since the start of the pandemic, although several of the schemes have started to expire in September-October 2020.

CAREC countries should consider implementing wage subsidy schemes to help protect jobs in the aviation and tourism sectors. Some CAREC countries are aiding workers impacted by the crisis by providing social benefits. While this aid is critical and should continue, wage subsidy schemes are critical to preserving jobs and mitigating the economic impact. Without wage subsidy schemes, companies may struggle to rehire workers once the downturn ends. There is also a risk that workers trained in aviation and tourism will take jobs in other sectors, inhibiting the ability of the aviation and tourism sectors to recover once demand returns.

Finally, CAREC countries should consider aviation specific support measures such as reductions in ticket taxes, airport fees, licensing, fees, and air navigation charges. Some CAREC countries have already implemented some of these measures but the amount of relief provided is generally small. Several CAREC countries have not provided any relief for aviation companies at all.

It is important for all CAREC countries to offer relief in aviation-related fees, charges, and taxes during these incredibly challenging times. Airlines need as much support as possible to get through this period. Other aviation industry companies including airports, ground handlers, and aircraft maintenance providers would also benefit from reductions in charges, concession fees, and rentals.

\section{Recommendation: CAREC should consider providing financial support packages to airlines through loans and loan guarantees.}

Recommendation: CAREC should consider providing general support packages to the aviation and tourism industries through benefits such as wage subsidies, tax reductions, and fee waivers.

\section{B. CAREC Need: Funding for Air Navigation Service Providers to Offset Loss of Overflight Revenues}

Overflight revenues are relatively high in CAREC countries as CAREC airspace is used for a large portion of flights heading between Europe and Asia. There are significantly more flights using CAREC airspace that overfly the region rather than land or depart in CAREC countries.

For example, Mongolia handled 134,000 overflights in 2019 compared to only 18,000 local flights. The number of overflights has doubled in Mongolia since 2010 while the number of local flights has increased by around 50\%.

Azerbaijan handled 95,000 overflights in 2018 and Georgia handled 145,000 overflights in 2017. Overflight data is not available for most other CAREC countries. However, all CAREC countries combined (excluding the PRC) 
likely handled roughly 1 million annual overflights prior to COVID-19. The number of overflights will likely reduce by over $60 \%$ in 2020 , resulting in a revenue reduction of several hundred million dollars.

While air navigation service providers (ANSP) have costs associated with overflights, the revenues generated in a normal year are far greater than their costs, resulting in a surplus. Due to the sharp decline in Asia-Europe passenger flights, there will likely be a deficit in 2020 rather than surplus. This will create budgetary pressures on ANSPs as well as other entities that rely on overflight revenues.

Some CAREC countries rely on overflight revenues to help fund their aviation authorities. Overflight revenues are also sometimes used to help fund government-owned airlines and cross-subsidize other government entities outside aviation.

CAREC countries will need to find other options for funding those entities and functions that rely on overflight fees. CAREC countries could consider loans to bridge the gap until overflights return to their normal levels.

Air navigation upgrade projects may also be impacted by the reduction in overflight revenues. These projects are important for increasing capacity and improving safety. CAREC should look at other funding options to ensure air navigation modernization and upgrade projects remain on track.

Recommendation: CAREC should consider alternative funding options to offset the impact of reduced overflight revenues. 


\section{APPENDIX 1 Mongolia Case Study}

\section{Mongolia: Impact Assessment}

Estimated decline in passenger traffic for 2020:

\section{1 million}

Estimated decline in revenues for all Mongolian airlines for 2020:

\section{$\$ 120$ million}

Estimated decline in overflights for 2020:

\section{4,000}

Estimated decline in visitor numbers for 2020:

\section{5,000}

Estimated economic impact on gross domestic product for 2020:

\section{\$1.1 billion}

Jobs at risk:

60,000

\section{Mongolia: Before the Pandemic}

Travel and tourism accounted for around 12\% of Mongolia's gross domestic product (GDP) prior to the the coronavirus disease (COVID-19) crisis, generating over $\$ 1.5$ billion (based on data from the Government of Mongolia). Mongolia's GDP was MNT36.9 trillion in 2019 (\$14.4 billion), an increase of 5.1\% compared to 2018.

Mongolia reported a 6.2\% GDP increase in 2018, marking the first time GDP growth exceeded 5\% since 2014. The tourism and aviation sectors were key drivers in the acceleration of GDP growth in 2018 and 2019.

Visitor numbers to Mongolia increased by 13\% in 2018 and $9 \%$ in 2019. Tourism in Mongolia started picking up in 2017 , when visitor numbers increased by $16 \%$, ending several years of flattish growth. The 404,000 visitors from 2016 equaled the 404,000 visitors from a decade earlier in 2006, but in the subsequent 3 years surged by $43 \%$ to 577,000 . 
Figure A1.1: Visitors to Mongolia, 1999-2019

(in thousands)

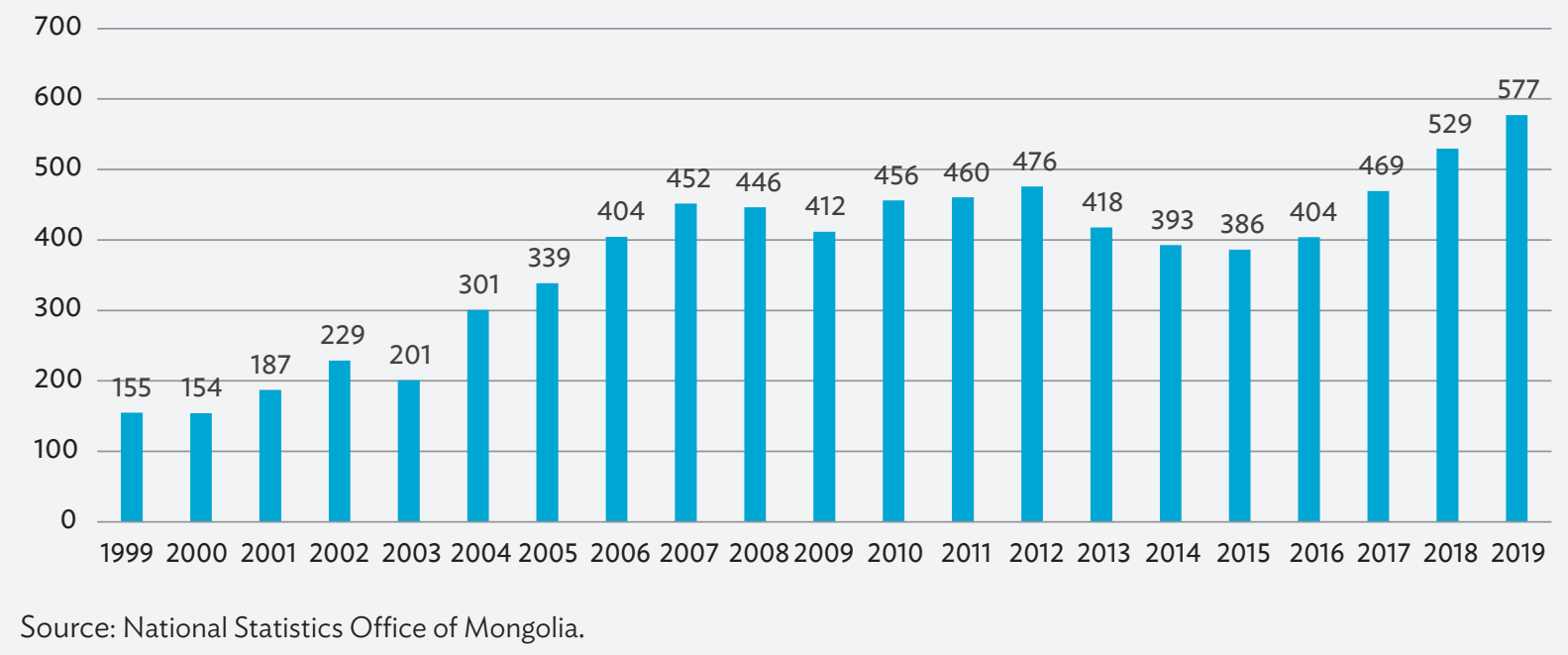

The last growth spurt occurred in 2003 to 2006, when visitor numbers doubled. Mongolia's tourism industry subsequently underperformed for several years while other emerging markets grew rapidly. Limited air access, due in part to protectionist policies, contributed to the lackluster growth rates.

Mongolia has liberalized its air transport sector over the last 3 years, resulting in improved air access that has driven faster international passenger growth and enabled the recent surge in visitor numbers.

International passenger traffic grew by 50\% from 2016 to 2019, including 16\% in 2019. International passenger traffic exceeded 1 million for the first time in 2018 and reached 1.2 million in 2019.

Figure A1.2: Mongolia Annual Domestic and International Passenger Traffic: 1999-2019 (in thousands)

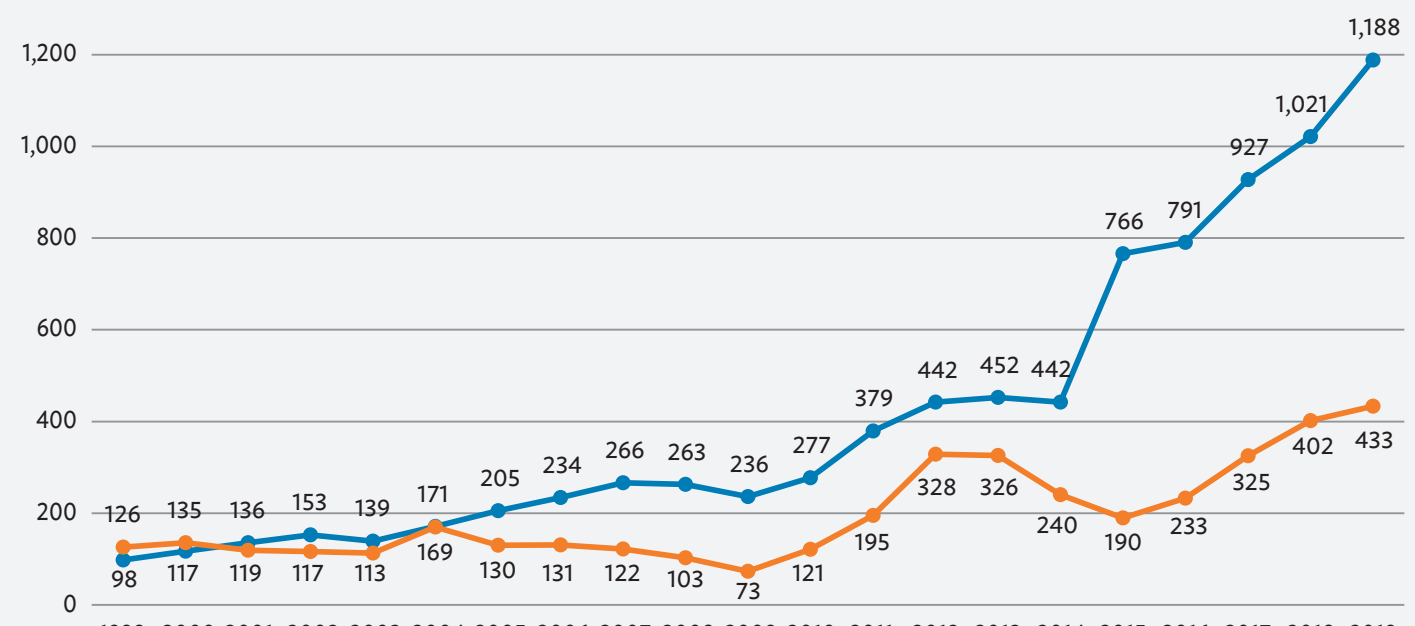

199920002001200220032004200520062007200820092010201120122013201420152016201720182019

$$
\longrightarrow \text { International Domestic }
$$

Source: National Statistics Office of Mongolia. 
Domestic passenger traffic grew at an even faster 86\% clip from 2016 to 2019. Mongolia's domestic air transport market exceeded 400,000 passengers for the first time in 2018 and reached 433,000 in 2019.

While visitor numbers were stagnant from 2006 to 2016, international passenger traffic more than tripled over this period due to rapid growth of the outbound segment as more Mongolians traveled overseas. The portion of the Mongolian population that traveled overseas has continued to grow the last 3 years, helping drive the overall growth in international passenger traffic along with the surge in visitor numbers.

The number of Mongolians departing Ulaanbaatar's Chinggis Khan International Airport increased by $46 \%$ from 2016 to 2019. In 2019, Mongolians accounted for slightly over half of total international passenger traffic.

Mongolia's domestic air transport market relies mainly on visitors and workers, including foreigners working in mining sites. The biggest domestic route is Ulaanbaatar to Oyu Tolgoi, a Rio Tinto mining site that has one of the world's largest copper and gold deposits. This route accounted for 275,000 or $64 \%$ of total domestic passenger traffic in 2019. Mining accounted for 24\% of Mongolia's GDP in 2019. A major expansion is underway at Oyu Tolgoi, which is expected to quadruple production over the next 5 years (although delays in the expansion project due to COVID-19 are now expected) and should lead to further domestic air transport growth.

While mining is a bigger economic contributor, tourism is important and prior to the pandemic was expected to assume an expanding role in Mongolia's economy. Mongolia had been projecting that by 2028 annual visitor numbers would surpass 1 million with tourism contributing $\$ 2.1$ billion to GDP and supporting 149,000 jobs.

\section{The Impact of the Pandemic}

COVID-19 has significantly impacted Mongolia's tourism growth aspirations-as it has in other CAREC countries and globally. Mongolia was impacted by COVID-19 earlier than other countries due to its proximity to the People's Republic of China (PRC). Mongolia closed all its borders with the PRC on 1 February and flights to the PRC, including Hong Kong, China were suspended.

Flights to the Republic of Korea and Japan were suspended on 26 February. All other international flights were suspended on 11 March as Mongolia also closed all its borders with the Russian Federation. As of early October, Mongolia had not yet reopened any borders or resumed any scheduled international flights.

The land borders with the Russian Federation and the PRC are critical for trade, which has continued during the pandemic, and also support outbound and inbound tourism flows. In 2019 nearly 2.5 million people (foreigners and locals) entered Mongolia using the land borders with the PRC and the Russian Federation.

The PRC, the Russian Federation, the Republic of Korea, and Japan are Mongolia's four largest source market for tourism, accounting for $75 \%$ of all visitors in 2019. They are also Mongolia's four largest air transport markets, accounting for over 90\% of international passenger traffic in 2019.

The closure of all borders and suspension of all scheduled international flights has been extended several times since March. Only chartered flights organized to repatriate foreign nationals that were stranded in Mongolia and Mongolians that were stranded overseas have been excluded from these bans.

The impact on tourism and aviation is potentially devastating. As with other CAREC countries, there was initially a hope that some of the summer tourist season could be salvaged by establishing green lanes or reopening 
borders with certain countries. However, Mongolia has still not yet pursued any green lanes and it now seems that borders will only reopen in spring or summer 2021 at the earliest.

This study projects a decline in visitor numbers of $89 \%$ for 2020. Mongolia's National Statistics Office reported 53,000 inbound tourists for the first three quarters of 2020 , a decline of $89 \%$ compared to the first three quarters of 2019 .

This study projects a 90\% decline in international passenger traffic (over 1 million fewer passengers). Passenger traffic has been limited since March to charter flights catering to repatriating citizens and foreign workers from the mining sector. The charters have carried only approximately 20,000 passengers in total.

A recovery in 2021 is now uncertain and would hinge on the borders reopening by next summer. As the pandemic may not end until after summer 2021, Mongolia should consider establishing green lanes in 2021 with select countries to facilitate a partial recovery of international traffic and resumption of tourism.

The Republic of Korea could be the first green lane for Mongolia, providing a boost for the inbound and outbound segments. A green lane between Mongolia and the Republic of Korea is logical given both countries' successful COVID-19 containment efforts and close ties.

In 2019, the Republic of Korea attracted 114,000 Mongolian visitors in 2019 while Mongolia attracted 101,000 Korean visitors. Both segments have been growing fast; Korean visitor numbers to Mongolia have more than doubled since 2015 while Mongolian visitor numbers to the Republic of Korea have increased by nearly $70 \%$ in the same period.

While the PRC (168,000 visitors in 2019) and the Russian Federation (142,000 visitors) are larger source markets for Mongolia, the Republic of Korea has a bigger impact on aviation given that a large portion of Chinese and Russian visitors cross by land.

Seoul is Ulaanbaatar's largest international route with 388,000 passengers in 2019 . Busan in the Republic of Korea is the sixth-largest route with 65,000 passengers.

Beijing was the second largest (214,000 passengers in 2019); followed by Moscow (95,000 passengers); Hong Kong, China (89,000 passengers); and Tokyo (79,000 passengers). In addition to catering to local traffic, Seoul; Beijing; Moscow; Hong Kong, China; and Tokyo are the most popular transit points for travel between Mongolia and countries that are not served nonstop.

Germany, Kazakhstan, Thailand, and Turkey are the only countries served nonstop from Ulaanbaatar in addition to the main four markets of the Republic of Korea, the PRC, the Russian Federation, and Japan. Nur-Sultan in Kazakhstan is a new route that was launched in 2019. Istanbul was upgraded in January 2020 to nonstop and was previously served one-stop service via Bishkek in the Kyrgyz Republic.

Domestic flights within Mongolia have continued during the pandemic. Domestic traffic has been impacted by the decline in tourism and the overall economy. However, the impact is mitigated by continued activity at Oyu Tolgoi and an increase in Mongolians traveling domestically for holidays due to the closure of international borders. While most Mongolians travel domestically by car, particularly when taking family holidays, there has been an increase in locals flying domestically during the pandemic.

This study projects a modest 10\% decline in domestic passenger traffic (43,000 fewer passengers) in 2020, driven by declines at small regional airports near tourist attractions such as the Gobi Desert and Khuvsgul Lake. 


\section{Ulaanbaatar's New Airport}

Mongolia was planning to open a new international airport outside Ulaanbaatar this summer. However, shortly after the start of the pandemic the new airport's private operator NUBIA informed the government it will not be able to open the airport by 1 July as initially required due to the pandemic, citing a force majeure clause in the contract.

The airport was initially slated to open in 2018, when most construction was completed, but was set back my multiple delays as it took longer than expected to finalize a concession agreement. A 15-year concession agreement was finally concluded in 2019 with NUBIA, a Japanese-Mongolian joint venture company. Mitsubishi, Narita International Airport, Japan Airport Terminal, and Jalux are the Japanese companies participating in the consortium.

A new opening date has not been confirmed but is now expected to take place sometime in 2021, possibly just prior to the start of the summer season. The New Ulaanbaatar International Airport is an important component of Mongolia's aspirations to grow passenger traffic and tourism. A recovery from COVID-19 is now critical in order for Mongolia to benefit from this major investment and the additional capacity.

The new airport will have initial capacity for 3 million passenger per annum and provides ample space for further expansion to meet future demand. It also provides 24 -hour all-weather access which will help attract more foreign airlines that have been reluctant to launch services to Mongolia due to the limitations at the current airport.

Ulaanbaatar's current airport, which is located closer to the city, has a single runway that can only be used in one direction for takeoffs and one direction for landings due to the proximity of mountains. These limitations often result in delays and cancellations as the airport has to be closed in poor weather or strong winds. A lack of alternative airports in Mongolia capable of handling large aircraft has been a further impediment, forcing diversions outside the country when the existing airport's unidirectional runway is not usable.

Prior to COVID-19, the New Ulaanbaatar International Airport would likely have reached 2 million annual passengers in 2021 and 3 million passengers by 2025. It is now likely the Mongolian market will not return to pre-COVID-19 level until 2023. Therefore, the new airport may not be able to reach 2 million passengers until 2025 or 2026 and 3 million passengers until 2029 or 2030.

\section{The Economic Impact}

The economic impact of COVID-19 will also be significant. For the first half of 2020 Mongolia reported a 9.7\% decline in GDP to MNT16.8 trillion ( $\$ 5.9$ billion). A double-digit GDP decline is likely for the full year, essentially erasing 2 years of economic growth.

Tourism's contribution to GDP could decline by $\$ 1.1$ billion, which alone would drive a nearly $8 \%$ drop in GDP. The impact on tourism businesses and the over 120,000 jobs they generate (based on the Government of Mongolia data) will have a ripple effect on the overall economy. This study estimates that 70,000 jobs in the travel and tourism sectors are now at risk.

Tourism in Mongolia is highly seasonal with businesses relying on a relatively short summer season to cover their year-round costs and wages. Without the typical summer season in 2020, businesses are now essentially weathering an exceptionally long 20-month off season and could struggle to stay in business. 
Domestic tourism has become important and will continue to play an enhanced role until border restrictions, which have made it impossible for Mongolians to travel abroad, are finally lifted. However, for most businesses an increase in domestic tourism is not enough to overcome the huge loss of revenues from overseas visitors. Domestic tourists spend less on average and some resorts and hotels rely almost entirely on foreigners.

\section{The Impact on Airlines}

For aviation, the uptick in domestic tourism is muted somewhat by the fact that Mongolians typically drive rather than fly when holidaying within the country. Two of Mongolia's airlines, MIAT Mongolian Airlines and Eznis Airways, also do not operate any scheduled domestic services.

Privately owned Eznis is particularly vulnerable as they are new, having launched operations in 2019. Eznis has only one aircraft, a 737-700, and was operating only one scheduled route (Hong Kong, China) prior to the pandemic. As Mongolia's first low cost carrier, Eznis had ambitious plans for international expansion and were intending to start a domestic operation in 2020 with a second aircraft type. However, expansion has been put on hold due to COVID-19 and the airline may struggle to survive the crisis.

MIAT is a government-owned flag carrier and Mongolia's largest airline. It will require additional financial support from the government to make up for a revenue shortfall. MIAT already reported a revenue shortfall of MNT50 billion ( $\$ 18$ million) in the first quarter of 2020 as its first quarter revenues declined by over $50 \%$. A larger shortfall is likely for the full year due to suspension of all scheduled international services. However, MIAT has been able to weather the storm relatively well and avoid job cuts by generating charter and cargo revenues and reducing costs. MIAT has operated regular international charter flights, focusing on repatriating traffic, since March and also has continued to operate domestic charter flights to Oyu Tolgoi, carrying mining workers.

MIAT's expansion plan, which includes the delivery of new 737 MAX 8 and 787-9 aircrafts, may also be impacted by COVID-19 although its long-term strategy will likely remain intact. MIAT's expansion is an important component of the government's overall plan to grow tourism and position Ulaanbaatar's new airport as a hub.

MIAT's first 787 was slated to arrive in May 2021 and be used to launch services to North America. However, the delivery and the launch of North America flights is now likely to be delayed until at least 2022.

Four 737 MAX 8, which offers improved range over the 737-800, will be used to expand in Eastern Europe and Asia. MIAT had one 737 MAX when the type was grounded globally in March 2019 and has commitments for another three, which were initially slated to be delivered in 2019 and 2020. It is now unlikely that MIAT will take delivery of these aircraft until at least 2022 as it aims to operate a smaller fleet until the pandemic is over.

MIAT's fleet is currently limited to three 737-800s and two 767s. One of the 737-800s is currently grounded and one of the 767s is due to be returned to its lessor in January 2021.

Privately owned Aero Mongolia and Hunnu Air mainly operate in the domestic market so are less impacted. However, both had international expansion plans using newly acquired regional jets. Their domestic traffic also has been impacted by the lack of international tourists, which typically account for most domestic passengers in Mongolia during the summer months.

Aero Mongolia and Hunnu were significantly impacted by Mongolia's decision to ban from early 2019 Fokker 50s, which had been the workhorse in Mongolia's domestic market for decades. Aero Mongolia now operates Embraer 
ERJ-145s and Hunnu operates ATR 72s as well as Embraer E190s. While Fokker 50s were ageing and expensive to maintain, they had the ability to operate into small airstrips that have since lost air service.

Mongolia's four airlines combined generated MNT499 billion (\$194 million) in revenues in 2019. Mongolian airline revenues have nearly doubled since 2015 , when they generated a combined MNT254 billion. This study estimates a $\$ 120$ million decline in airline revenues for 2020 with MIAT accounting for most of the shortfall.

\section{Government Support}

As MIAT is 100\% government-owned, it should be able to secure the financial support to survive the crisis. The airline has so far not needed a capital infusion but may need to boost liquidity in 2021, depending on how long the crisis lasts and how quickly it can recover. MIAT will also likely require more capital at some point to cover future investments that are needed to support growth aspirations.

Allocating funds for the airline could be challenging given the budgetary pressures and social requirements that have resulted from the pandemic. The government will also need to make up for a shortfall in overflight fees.

Mongolia handled 134,000 overflights in 2019. The number of overflights has doubled since 2010 as global air traffic has increased rapidly. Mongolian airspace is often used for flights between Asia and Europe as well as polar flights heading between Asia and eastern North America. Due to the huge reduction in international flights due to COVID-19, this study estimates a 70\% reduction in overflights and overflight revenues in 2020.

The revenues generated from other aviation related fees and taxes will also be reduced due to the decline in flights to, from and within Mongolia. It is unclear how Mongolia and other CAREC countries will cover these shortfalls but likely they will result in further budgetary pressures during what is a very challenging time.

Mongolia may also need to support private companies in the aviation and tourism sectors in order to ensure their survival. Some support has been provided including a wage subsidy scheme that covered for 3 months a portion of salaries for workers in industries impacted by COVID-19. Mongolia may need to consider more extensive support for aviation and tourism, which should be justified given the importance of these sectors to the overall economy.

Mongolia should consider soft loans to help small aviation and tourism businesses. The government could also consider extending or reintroducing employee support schemes to help cover wages and protect jobs.

Without government support the impact on aviation and tourism could be devastating and irreversible. A recovery in 2022 is not possible if the businesses and employees are no longer in place.

\section{Opportunities and Needs}

The Asian Development Bank (ADB) has funded several transport and tourism related projects in Mongolia in recent years. ADB also announced in May 2020 a $\$ 100$ million loan to the Government of Mongolia to help mitigate the health and economic impact of the COVID-19 pandemic. ${ }^{1}$ These funds are aimed at helping out

ADB. 2020. ADB Provides $\$ 100$ million to Support Mongolia's COVID-19 Response. 12 May. https://www.adb.org/news/adb-provides-100-millionsupport-mongolias-covid-19-response. 
vulnerable businesses as well as individuals. Small businesses that rely heavily on tourism should be able to benefit from this program.

Support for aviation could be considered given its critical role in the overall economy and tourism. Mongolia's aviation industry needs to survive this crisis and be developed to support the tourism strategy.

ADB can provide technical assistance by funding an air transport liberalization study, which was initially planned for 2019. Mongolia has been liberalizing its air transport market and could use assistance in developing the right strategies to identify impediments and unlock growth. This is even more important given the impact of COVID-19 and the upcoming opening of Ulaanbaatar's new airport.

It is a critical time for aviation and tourism. With the right strategies and investments, Mongolia can recover fast and resume growth.

Until the end of the pandemic, Mongolia could position itself as a safe destination given its successful COVID-19 containment efforts and remoteness. Holidaying in Mongolia is about enjoying open spaces, breathtaking scenery and nature. It is an ideal destination for the current social distancing environment.

Ecotourism is also a focus of Mongolia's long-term tourism growth strategy. ADB has already invested in two ecotourism projects in Mongolia as part of ADB's initiative to promote and invest in sustainable tourism.

Both of ADB's ecotourism projects in Mongolia would benefit from improved air access. The first project is at Khuvsgul Lake National Park, one of Mongolia's most popular tourist destinations, and the second project is at less visited Onon-Balj National Park, the birthplace of Chinggis Khan. ${ }^{2}$ A new airport has been under consideration for Onon-Balj while Khuvsgul Lake is accessed by using the existing airport at Moron, the capital of Khuvsgul province. An upgrade for Moron Airport is planned to accommodate jets, which would allow more regular domestic services from Ulaanbaatar as well seasonal international charters from the Republic of Korea.

Khuvsgul Lake is a popular destination, particularly for Koreans, and could experience a significant increase in visitors with improved air access, which is only possible by upgrading the airport. The International Finance Corporation has decided not to proceed with financing the Moron Airport upgrade project. ADB could consider stepping in given Moron Airport's importance in developing the Khuvsgul Lake region and Mongolia as an ecotourism destination. There are several other regional airport upgrade projects under consideration that would help support Mongolia's position as an ecotourism destination and tourism growth aspirations.

Now is the time to invest in the future and put in place the right strategies to facilitate Mongolia's development. Mongolia has huge aviation and tourism potential but this can only be unlocked with closely coordinated and implemented strategies for both sectors. COVID-19 is creating a host of challenges but this crisis is also an opportunity to reset the strategy and pursue reforms.

Similar tourism and related aviation investments are needed throughout CAREC as member countries try to recover from COVID-19. In this initial impact study, Mongolia is highlighted as just one example. Other examples can be outlined in future phases of this project.

2 ADB. 2019. ADB Starts Second Eco-Tourism Project for Mongolia's National Parks. 19 October. https://www.adb.org/news/adb-starts-second-ecotourism-project-mongolias-national-parks. 


\section{APPENDIX 2 Survey Results}

In June 2020, shortly after the initial draft of the COVID-19 impact assessment study on CAREC Aviation and Tourism was completed, CAREC sent a survey to all the member countries. Eight of the 11 CAREC countries filled out and returned the survey.

Virtual conferences were also offered to further discuss the study and the recommendations. Virtual conferences with three countries were subsequently held in July 2020.

The survey covered three main areas-the 11 recommendations, how countries were aiding airlines and how countries quantified the impact of COVID-19 on aviation and tourism. The results have been used to gauge if there is consensus with the proposed recommendations. It also has been used to provide additional data and information for incorporation in the final version of the report.

\section{Survey Part A: COVID-19 Impact Study Recommendations}

Results from the first part of the survey indicate that CAREC countries agree on almost all the recommendations that were included in the initial draft of the study, which was shared with member countries in June 2020.

A 12th recommendation has been added to the final version of the study following suggestions from the People's Republic of China. The final version of the study also tweaks the language of the first recommendation, removing a reference to the second half 2020 . This recommendation, which related to promotion of domestic tourism, is also relevant for 2021 given the continuation of the pandemic and the very slow pace of recovery for international tourism.

Below is a summary tally on how the eight countries replied when asked if they agree to each of the recommendations. For five of the recommendations, all eight Central Asia Regional Economic Cooperation (CAREC) countries that replied to the survey ticked the "Yes" box; for another five of the recommendations, six of the countries agreed and for one recommendation, five countries agreed. The total number of survey responses does not equal eight for all the recommendations as one country did not check either the "Yes" or "No" box to some of the recommendations.

(1) CAREC should promote domestic tourism in the second half 2020 to help facilitate a recovery of the aviation and tourism sectors during a period of much lower international traffic.

\begin{tabular}{|c|c|}
\hline Yes & No \\
\hline 8 & \\
\hline
\end{tabular}


(2) CAREC countries should consider opening green lanes to facilitate and stimulate travel and tourism within CAREC.

\begin{tabular}{|c|c|}
\hline Yes & No \\
\hline 8 & \\
\hline
\end{tabular}

(3) CAREC countries should consider implementing a visa-free policy to further facilitate travel and tourism within CAREC.

\begin{tabular}{|c|c|}
\hline Yes & No \\
\hline 6 & 1 \\
\hline
\end{tabular}

(4) CAREC should promote improved air connectivity between CAREC countries during the pandemic and after this crisis.

\begin{tabular}{|c|c|}
\hline Yes & No \\
\hline 7 & \\
\hline
\end{tabular}

(5) CAREC should consider providing incentives to support the launch of new routes connecting major cities with tourist destinations in other CAREC countries.

\begin{tabular}{|c|c|}
\hline Yes & No \\
\hline 7 & 1 \\
\hline
\end{tabular}

(6) CAREC should invest in boosting air cargo capabilities, leveraging its strategic location between Asia and Europe and driving increased cargo revenues for the aviation industry during a period of passenger declines.

\begin{tabular}{|c|c|}
\hline 7 & Nos \\
\hline 7 & \\
\hline
\end{tabular}

(7) CAREC should promote contactless air travel and invest in technologies to support digital procedures at airports.

\begin{tabular}{|c|c|}
\hline Yes & No \\
\hline 8 & \\
\hline
\end{tabular}

(8) CAREC should adopt uniform standards and regulations for air travel in the COVID-19 environment.

\begin{tabular}{|c|c|}
\hline Yes & No \\
\hline 8 & \\
\hline
\end{tabular}

(9) CAREC should consider providing financial support to airlines through loans and loan guarantees.

\begin{tabular}{|c|c|}
\hline Yes & No \\
\hline 8 & \\
\hline
\end{tabular}

(10) CAREC should consider providing general support packages to the aviation and tourism industries through benefits such as wage subsidies, tax reductions, and fee waivers.

\begin{tabular}{|c|c|}
\hline Yes & No \\
\hline 7 & \\
\hline
\end{tabular}

(11) CAREC should consider alternative funding options to offset the impact of reduced overflight revenues.

\begin{tabular}{|c|c|}
\hline Yes & No \\
\hline 7 & 1 \\
\hline
\end{tabular}




\section{Survey Part B: COVID-19 Airline Aid}

Results from the second section of the survey indicate that most countries have not provided coronavirus disease (COVID-19)-related financial assistance or other benefits to their airlines. The lack of government support for airlines in CAREC could have ramifications as most major countries globally have provided financial and general support for their airline sectors.

CAREC countries were asked about 12 specific benefits that have been provided by many countries in other regions. It also included an additional question on other benefits that have been provided if applicable.

Of the 12 specific benefits, four have not been provided by any country. Six benefits have been provided by two countries and one have been provided by three countries. The remaining one benefit has been provided by one country. For the question on other benefits, four countries provided a list and four said no other benefits were provided.

As in the case with Part $\mathrm{A}$, the total number of survey responses does not equal eight to all questions as some countries chose not to reply to some of the questions.

It is possible that some CAREC countries decided more recently to provide airlines with financial assistance or other benefits. While most countries in other regions announced airline support packages in the initial months of the crisis - generally April and May - a few countries did not come out with support packages until more recently.

Below is a summary tally showing the number of countries that replied yes and no to each question.

(1) Reduced or waived landing fees

\begin{tabular}{|c|c|}
\hline Yes & No \\
\hline 2 & 6 \\
\hline
\end{tabular}

(2) Reduced or waived airport parking fees

\begin{tabular}{|c|c|}
\hline Yes & No \\
\hline 2 & 6 \\
\hline
\end{tabular}

(3) Reduced or waived airport aerobridge fees

\begin{tabular}{|c|c|}
\hline Yes & No \\
\hline & 6 \\
\hline
\end{tabular}

(4) Reduced or waived income taxes

\begin{tabular}{|c|c|}
\hline Yes & No \\
\hline 2 & 5 \\
\hline
\end{tabular}

(5) Reduced or waived VAT

\begin{tabular}{|c|c|}
\hline Yes & No \\
\hline 2 & 6 \\
\hline
\end{tabular}

(6) Reduced or waived rentals on offices and other facilities (i.e., hangars)

\begin{tabular}{|c|c|}
\hline Yes & No \\
\hline 3 & 5 \\
\hline
\end{tabular}


(7) Subsidies or grants for maintaining domestic services

\begin{tabular}{|l|c|}
\multicolumn{1}{l|}{ Yes } & No \\
\hline & 7 \\
\hline
\end{tabular}

(8) Subsidies or grants for international repatriation flights

\begin{tabular}{|c|c|}
\hline \multicolumn{1}{|c|}{ Yes } & No \\
\hline 2 & 5 \\
\hline
\end{tabular}

(9) Wage subsidies for airline employees

\begin{tabular}{|l|c|}
\hline \multicolumn{1}{|c}{ Yes } & No \\
\hline & 7 \\
\hline
\end{tabular}

(10) Government loans

\begin{tabular}{|c|c|}
\hline \multicolumn{1}{|c|}{ Yes } & No \\
\hline 2 & 5 \\
\hline
\end{tabular}

(11) Government loan guarantees

\begin{tabular}{|c|c|}
\hline Yes & No \\
\hline 1 & 6 \\
\hline
\end{tabular}

(12) Cash injections (only applicable to government-owned airlines)

\begin{tabular}{|l|c|}
\hline \multicolumn{1}{l|}{ Yes } & No \\
\hline & 7 \\
\hline
\end{tabular}

(13) Other benefits

\begin{tabular}{|c|c|}
\hline \multicolumn{1}{|c|}{ Yes } & No \\
\hline 4 & 4 \\
\hline
\end{tabular}

\section{Survey Part C: Qualifying the Impact of COVID-19}

Results from the third section of the survey indicate a significant impact of COVID-19 on aviation and tourism companies and a high risk of bankruptcies.

CAREC countries were asked to rate on a five-point scale the financial situation of four different types of companies-airlines, airports, hotels and tourism operators. They were also asked to rate on a five-point scale the revenue impact on two types of companies - airlines and airports-as well as on the overall aviation and tourism sectors. The most common reply was a $60 \%-80 \%$ revenue impact across all the categories while tourism operators were deemed to be closest to bankruptcy.

Given that the resumption of international air travel and international tourism has been slower than initially anticipated, the survey responses by many countries would likely be further to the right, indicating an even higher impact on revenue and a direr financial situation, if this survey was repeated more recently.

As in the case with the first two parts, the total number of survey responses does not equal eight to all questions as some countries chose not to reply to some of the questions. 
The tallies below show the number of countries checking each box in the five-point scale for each of the eight questions.

(1) How would you rate on a five-point scale the current financial situation of passenger airlines in your country:

Strong liquidity/No

Dire/Near

Bankruptcy Risk Bankruptcy

\begin{tabular}{|l|l|l|l|l|}
\hline & & 3 & 2 & \\
\hline
\end{tabular}

(2) How would you rate on a five-point scale the current financial situation of airports in your country:

\section{Strong liquidity/No}

Bankruptcy Risk

Dire/Near

Bankruptcy

\begin{tabular}{|l|l|l|l|l|}
\hline & 1 & 4 & 1 & \\
\hline
\end{tabular}

(3) How would you rate on a five-point scale the current financial situation of hotels in your country:

\section{Strong liquidity/No \\ Bankruptcy Risk}

\begin{tabular}{|l|l|c|c|}
\multicolumn{2}{c}{} & $\begin{array}{c}\text { Dire/Near } \\
\text { Bankruptcy }\end{array}$ \\
\hline 2 & 1 & 2 & 1 \\
\hline
\end{tabular}

(4) How would you rate on a five-point scale the current financial situation of tourism operators in your country:

Strong liquidity/No

Dire/Near

Bankruptcy Risk Bankruptcy

\begin{tabular}{|c|c|c|c|c|}
\hline 1 & 1 & 2 & 2 \\
\hline
\end{tabular}

(5) How would you qualify the expected revenue impact for 2020 on airlines:

Less than $20 \%$ $20 \%$ to $40 \%$ $40 \%$ to $60 \%$ $60 \%$ to $80 \%$ Over $\mathbf{8 0 \%}$

\begin{tabular}{|l|l|l|l|l|}
\hline & 1 & 1 & 3 & \\
\hline
\end{tabular}

(6) How would you qualify the expected revenue impact for 2020 on airports:

Less than $20 \%$ $20 \%$ to $40 \%$ $40 \%$ to $60 \%$ $60 \%$ to $80 \%$ Over $\mathbf{8 0 \%}$

\begin{tabular}{|l|l|l|l|l|}
\hline & 2 & 1 & 3 & \\
\hline
\end{tabular}

(7) How would you qualify the expected revenue impact for 2020 on the aviation sector overall:

Less than $20 \%$ $20 \%$ to $40 \%$ $40 \%$ to $60 \%$ $60 \%$ to $80 \%$ Over $80 \%$

\begin{tabular}{|c|c|c|c|c|}
\hline & 1 & 1 & 3 & \\
\hline
\end{tabular}

(8) How would you qualify the expected revenue impact for 2020 on the tourism sector overall:

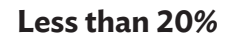
$20 \%$ to $40 \%$ $40 \%$ to $60 \%$ $60 \%$ to $80 \%$ Over $\mathbf{8 0 \%}$ 1

$\%$

1




\title{
Impact of COVID-19 on CAREC Aviation and Tourism
}

The coronavirus disease (COVID-19) has had a devastating impact on global aviation as nearly all air travel came to a halt in late March and April 2020. In Central Asia, virtually all domestic and international air travel were suspended in an attempt to contain the spread of COVID-19. This crisis provides an opportunity to reset the aviation industry in Central Asia Regional Cooperation (CAREC) countries through reforms, new strategies, and restructurings. This study of the pandemic's impact on CAREC and the aviation industry looks at the gravity of the situation, explores opportunities, and offers some recommendations for dealing with the crisis and facilitating a fast recovery.

\section{About the Central Asia Regional Economic Cooperation Program}

The Central Asia Regional Economic Cooperation (CAREC) Program is a partnership of 11 member countries and development partners working together to promote development through cooperation, leading to accelerated economic growth and poverty reduction. It is guided by the overarching vision of "Good Neighbors, Good Partners, and Good Prospects." CAREC countries include Afghanistan, Azerbaijan, the People's Republic of China, Georgia, Kazakhstan, the Kyrgyz Republic, Mongolia, Pakistan, Tajikistan, Turkmenistan, and Uzbekistan.

\section{About the Asian Development Bank}

ADB is committed to achieving a prosperous, inclusive, resilient, and sustainable Asia and the Pacific, while sustaining its efforts to eradicate extreme poverty. Established in 1966, it is owned by 68 members -49 from the region. Its main instruments for helping its developing member countries are policy dialogue, loans, equity investments, guarantees, grants, and technical assistance.

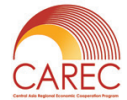

\section{CAREC SECRETARIAT}

www.carecprogram.org

\author{
ASIAN DEVELOPMENT BANK \\ 6 ADB Avenue, Mandaluyong City \\ 1550 Metro Manila, Philippines \\ www.adb.org
}

